\title{
Online Monitoring Technique of Power Condition for Inverter-Fed Motor Driven Hydraulic System
}

\author{
Lichen Gu (i) and Yuan Shi (i) \\ School of Mechanical and Electronic Engineering, Xian University of Architecture and Technology, Xian 710055, China \\ Correspondence should be addressed to Yuan Shi; shiyuan@xauat.edu.cn
}

Received 1 February 2019; Revised 1 April 2019; Accepted 17 April 2019; Published 5 May 2019

Academic Editor: Changzhi Wu

Copyright (C) 2019 Lichen Gu and Yuan Shi. This is an open access article distributed under the Creative Commons Attribution License, which permits unrestricted use, distribution, and reproduction in any medium, provided the original work is properly cited.

\begin{abstract}
As a new type of global energy-saving transmission mode, frequency conversion hydraulic drive system has been widely used. Since hydraulic systems become more complex and transfer more power, operating accidents often occur unexpectedly. Therefore, online monitoring of the running state of the hydraulic system is significant during its long-term operation. The pressure, flow, and vibration signals obtained by traditional monitoring methods are nonstationary and susceptible to disturbance. In order to solve this problem, a method of monitoring power condition of the motor driven hydraulic system based on input voltage and current of the motor is proposed. The present study uses the amplitude and phase information of the voltage and current signals on the stator side of the AC motor to form a dynamic power circle graph and extracts feature information from the graph to monitor the power state and its dynamic change process of the hydraulic system. Results obtained from experiments conducted under different frequencies and loads indicate that the proposed method can realize the online monitoring successfully and effectively. Furthermore, the method has another advantage of monitoring the dynamic power change process of the hydraulic drive system and the power matching process between the motor and the system load condition in a visualized way.
\end{abstract}

\section{Introduction}

Compared with the traditional asynchronous motor drive hydraulic system, the variable frequency drive (VFD) hydraulic system has the advantages of wide speed regulation range, small loss, and high system efficiency [1-3].Therefore, it has been rapidly developed and applied in the fields of hydraulic elevator, aircraft, injection molding machine, centrifuge, pumping unit, and coiler [4-6]. The increasing importance of these energy conversion devices and their wide application require the development of research work. State monitoring, energy saving control, and early fault prevention and diagnosis have been constantly studied [7-9].

During the operation of hydraulic equipment, the mechanical, electrical, and hydraulic parameters are dynamic and coupled. In order to fully understand the operation state and the design and manufacture level of the equipment, the working conditions should be considered to comprehensively analyse the changing process of the mechanical, electrical, and hydraulic parameters. However, most of these parameters, such as vibration, force, torque, rotating speed, pressure, and flow, are obtained by embedded measurement method. They have limited feature information and are easy to be disturbed [10-12]. These signals have low signal-to-noise ratio and contain incomplete fault information due to the influence of multicoupling and strong coupling characteristics of the system, and the mutual interference among the loops in the system, etc. In addition, since the hydraulic components work in the closed oil circuit, the working process is not visible as that in mechanical transmission and the measurement of operating parameters is prone to interference.

Researchers have made a lot of achievements in state monitoring and fault diagnosis of motors by using the method based on electrical signal analysis [13-15]. The advantages of these studies are that there is no need to estimate current parameters and it is easy to install the current sensor. Therefore, in recent years, fault diagnosis based on electrical parameters has been extended to the transmission chain between motor and load. For instance, in the fault detection of gearbox driven by induction motor, the wear or fracture of gear teeth can be detected by analyzing the frequency spectrum of stator current or estimated electric torque [16, 


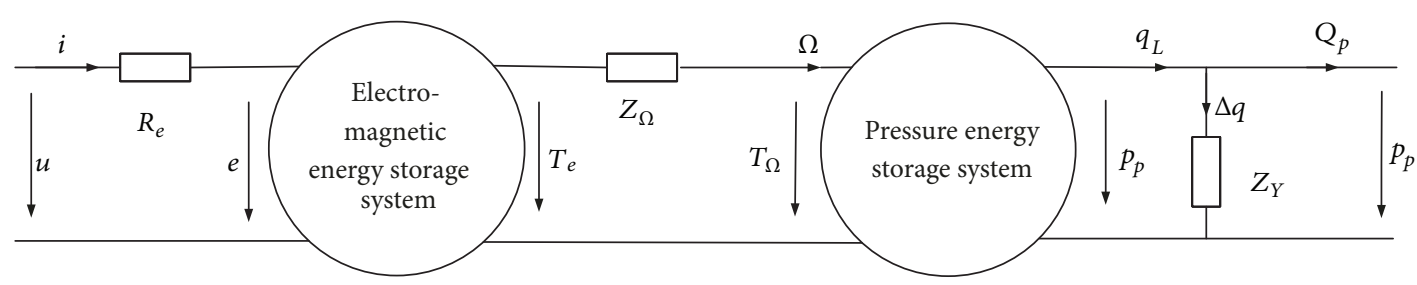

FIGURE 1: Two-port network model for energy transfer of motor driven hydraulic system.

17]. Reference [18] proposes a way of detecting faults by monitoring motor current or voltage to detect abnormal worktable of coal mill. Reference [19] presents a study in detecting misalignment between the motor axes and load by tracking the stator current and active power consumed by the motor. In [20], the method of detecting cavitation in hydraulic system by motor variable is studied. In [21], the method of extracting useful diagnostic information of motor current signal is used to monitor and diagnose the fault of centrifugal pump.

A large number of experimental studies and theoretical analyses have shown that the characteristic information, which reflects the running state, load change, and design defects of hydraulic equipment, is coupled with the electrical parameters of the motor by the mechanical and fluid parameters. This is because that the coupling effect exists between the stator and rotor of the motor during the operation of the motor drive equipment $[16,22,23]$. The changing process of the motor power contains characteristic information which reflects the operating state, the working condition, the load changing, and the power matching of the system. Therefore, it is a practical monitoring method to study the running state which is contained in the information of the electrical parameters of the operating equipment. However, the existing methods using electrical signals of motors are mostly based on frequency domain analysis and offline detection. Moreover, there is no visual monitoring technology to observe online the matching condition of the instantaneous power of the motor and the load. Therefore, a graphical monitoring method of power condition using the input voltage and current signal of the induction motor is proposed.

This paper is structured as follows. In Section 1, a detailed analytical analysis of the mechanical, electrical, and hydraulic energy conversion and coupling process is performed by establishing the dynamic power balance equation of the AC motor driven hydraulic system. In Section 2, the dynamic power circle equations and the corresponding power circle graphs are deduced through mathematical derivation. Furthermore, the characteristic information in the graphics, including the area, the tilt angle, and its changing direction of the power circle, is extracted, and the functional relationship between graphic features and physical quantities is obtained. A graphical monitoring method based on power circle is established to realize the online monitoring of the working state, the power condition, and the load of the hydraulic system. Section 3 presents the experiments under the condition of different supply frequencies and loads. In Section 4, the experimental results are discussed and the conclusion is drawn.

\section{Theoretical Development}

2.1. Energy Conversion Process of Hydraulic System. A motor driven hydraulic system mainly includes power supply, motor, hydraulic pump, hydraulic motor (or hydraulic cylinder), and load device. The energy transfer and conversion process of the hydraulic system can be illustrated by a twoport network model [24, 25], as shown in Figure 1.

In Figure 1, the input energy of the system is electric energy $(u, i)$, which is converted into coupling rotational kinetic energy $\left(T_{e}, \Omega\right)$ of the system state. The output energy of the system is fluid kinetic energy and pressure energy $\left(p_{p}, Q_{p}\right)$. The energy loss during the transmission includes electrical loss $R_{\mathrm{e}}$ and mechanical loss $Z_{\Omega}$ which includes friction and damping loss and fluid pressure loss $Z_{\mathrm{Y}}$ which includes liquid resistance loss and liquid sense loss.

During the energy conversion process of the motor driven hydraulic system, the motor, on one hand, generates inductive electromotive force in the circuit by the change of the stored electromagnetic energy caused by the current change, at the same time, it absorbs the outside electric energy. On the other hand, it generates electromagnetic torque and transforms magnetic energy into mechanical energy as the output. Thus, the conversion from electric energy to mechanical energy is realized, which is the electromechanical coupling process. On the one hand, the high pressure cavity of the hydraulic pump absorbs rotating mechanical energy from the output shaft of the motor. On the other hand, the fluid energy is the output from the outlet of the hydraulic pump. That is the mechanichydraulic coupling process.

According to the principle of power conservation, the power balance relation in the energy exchange process can be expressed as

$$
\begin{array}{r}
P_{\text {in }}=\Delta P_{\mathrm{R}}+P_{\mathrm{ms}}+P_{\mathrm{m}} \\
P_{\mathrm{m}}-\Delta P_{\mathrm{m}}=\Delta P_{1}+P_{\mathrm{ps}}+P_{\text {out }}
\end{array}
$$

where $P_{\text {in }}$ is the input power of the motor, $\Delta P_{\mathrm{R}}$ is the electrical resistance loss power of the motor, $P_{\mathrm{ms}}$ is the storage power of the motor, $P_{\mathrm{m}}$ is the mechanical output of the motor, $\Delta P_{\mathrm{m}}$ is the mechanical loss power, $\Delta P_{1}$ is the leakage loss power of the hydraulic pump, $P_{\mathrm{ps}}$ is the storage power of the high pressure chamber of the hydraulic pump, and $P_{\text {out }}$ is the output power of the hydraulic pump.

According to the coupling process in Figure 1, the electromagnetic torque of the motor $T_{\mathrm{e}}$ is used as the coupling variable during the electromechanical coupling process and the outlet pressure of the hydraulic pump $p_{\mathrm{p}}$ is used as the 
coupling variable during the mechanic-hydraulic coupling process.

Motor-hydraulic pump rotor system is a multivariable, strongly coupled, and nonlinear system. During the coupling process, working load determines the coupling variable $p_{p}$. When $p_{p}$ rises, current of the motor stator and rotor is increased by the electromechanical coupling variable $T_{e}$, and the vibration of the rotor system in $(x, y, z)$ direction is intensified. If the motor eccentricity increases due to manufacturing eccentricity or improper installation, vibration in the direction of $(x, y, z)$ will be coupled to the torsional vibration system, resulting in changes in current and hydraulic parameters. If the hydraulic pump fails, the pressure, efficiency, and flow rate of the hydraulic pump will change, and the current and vibration parameters will be affected by the coupling of the torsional vibration system. If the motor fails, such as short circuit and broken bar, the inductance must be changed, resulting in changes in electrical parameters. The following is to prove the functional relationship between electrical parameters and the working load and between the electrical parameters and the coupling variables from the perspective of power balance, so as to prove that the dynamic change of electrical parameters contains characteristic information of working conditions, loads, and operating states of the system.

2.2. Inverter-Motor Link. In frequency conversion control, the output of the converter is PWM wave, which contains a lot of harmonics. However, the motor torque mainly depends on the effective value of fundamental voltage. The stator current of the AC motor increases when it is supplied with variable frequency power, but the difference of the effective value of the stator current is basically unchanged. The difference between the stator current of the inverter-fed motor and its fundamental component is approximately constant and independent of the load. The total loss of variable frequency motor is obviously higher than that of sinusoidal power supply, but the difference between them is basically the same. That is, the total loss of the motor caused by the harmonic component of the converter is almost independent of the load [26]. Therefore, the present study uses the fundamental frequency signal of AC parameters.

$\mathrm{U} / \mathrm{f}$ control is an approximate constant flux control and a common control mode of open loop variable frequency speed control system. Ignoring the leakage impedance voltage drop of stator windings, the voltage of each phase of the AC motor is approximately equal to the electromotive force. It shows that the stator voltage changes with the power frequency and the ratio of the stator voltage to the power frequency is constant. On the premise that the flux of the motor remains unchanged, the magnitude of the electromagnetic torque depends on that of the rotor current. Therefore, the magnitude of the stator current of the motor is determined by the load torque, independent of the output frequency of the frequency converter.

Coordinate transformation does not affect the power balance relationship of the motor. Therefore, Clark coordinate transformation is used to simplify the model and eliminate time-varying inductance. Then, the effect of transformer electromotive force (EMF) and motion EMF in the electromechanical energy conversion process is decoupled [27]. The simplified voltage balance equation of three-phase asynchronous motor in two-phase static coordinate system is as follows[28]:

$$
\mathbf{u}=\mathbf{R i}+\mathbf{L p} \mathbf{i}+\mathbf{G} \omega_{r} \mathbf{i}
$$

Multiplying both ends of (3) by $\mathbf{i}^{T}$, the power balance equation of the motor can be obtained as follows:

$$
\mathbf{i}^{T} \mathbf{u}=\mathbf{i}^{T} \mathbf{R} \mathbf{i}+\mathbf{i}^{T} \mathbf{L p} \mathbf{i}+\mathbf{i}^{T} \mathbf{G} \omega_{r} \mathbf{i}
$$

where $\mathbf{i}^{\mathrm{T}} \mathbf{u}$ is the input power $P_{\mathrm{in}}, \mathbf{i}^{\mathrm{T}} \mathbf{R} \mathbf{i}$ is resistance loss power $P_{c}, \mathbf{i}^{\mathrm{T}} \mathbf{L} p \mathbf{i}$ is the stored power $P_{\mathrm{Q}}$ in the coupled magnetic field which corresponds to the transformer EMF and belongs to reactive power, and $\mathbf{i}^{T} \mathbf{G} \omega_{\mathrm{r}} \mathbf{i}$ is the output mechanical power $P_{\mathrm{m}}$ which corresponds to the motional EMF.

Torque balance equation on the motor shaft is expressed as follows [29]:

$$
J_{\mathrm{T}} \frac{\mathrm{d} \Omega}{\mathrm{d} t}=T_{\mathrm{e}}-T_{\mathrm{df}}-T_{\mathrm{m}}-B_{\mathrm{T}} \Omega
$$

Multiplying both sides of (5) by $\Omega$, the output power balance equation of the motor shaft is expressed by

$$
J_{\mathrm{T}} \Omega \frac{\mathrm{d} \Omega}{\mathrm{d} t}=T_{\mathrm{e}} \Omega-T_{\mathrm{df}} \Omega-T_{\mathrm{m}} \Omega-B_{\mathrm{T}} \Omega^{2}
$$

where $J_{\mathrm{T}} \Omega \mathrm{d} \Omega / \mathrm{d} t$ and $B_{\mathrm{T}} \Omega^{2}$ are the power stored on the drive shaft, $T_{\mathrm{e}} \Omega$ is the output power of the motor, $T_{\mathrm{df}} \Omega$ and $T_{\mathrm{m}} \Omega$ are mechanical loss power and the power absorbed by the hydraulic pump, respectively.

According to (4) and (6), the coupling variable $T_{\mathrm{e}}$ is expressed as follows:

$$
T_{\mathrm{e}}=\mathrm{n}_{\mathrm{p}} L_{\mathrm{m}}\left(i_{s \beta} i_{r \alpha}-i_{s \alpha} i_{r \beta}\right)
$$

Equations (4) and (6) are the balance equations of motor input and output power, and (7) is the electromechanical coupling equation.

2.3. Hydraulic Rotary System Link. Based on the theory of mechanical dynamics and fluid mechanics, the following assumptions are made: the pipeline pressure loss and dynamic process between pump and motor are neglected; the pulsation of hydraulic pump oil supply is neglected; the leakage flows of pump and motor are laminar flow; the output shaft of motor and its connecting parts are absolutely rigid connection.

2.3.1. Power Balance Equation of Hydraulic Pump. It is given that the theoretical flow, output flow, and leakage of the hydraulic pump are $Q_{L}, Q_{p}$, and $Q_{l p}$, respectively, and the flow caused by hydraulic compression is $Q_{p}$; then the flow balance equation of the hydraulic pump is [30]

$$
Q_{\mathrm{L}}=Q_{\mathrm{p}}+Q_{\mathrm{lp}}+Q_{\mathrm{ps}}
$$


Multiplying both sides of (8) by the system pressure, the power balance equation of the hydraulic pump is obtained as follows:

$$
p_{\mathrm{p}} \mathrm{Q}_{\mathrm{L}}=p_{\mathrm{p}} \mathrm{Q}_{\mathrm{p}}+p_{\mathrm{p}} \mathrm{Q}_{\mathrm{lp}}+p_{\mathrm{p}} \mathrm{Q}_{\mathrm{ps}}
$$

where $p_{\mathrm{p}} Q_{\mathrm{L}}$ and $p_{\mathrm{p}} Q_{\mathrm{p}}$ are the input power and output fluid power of the hydraulic pump and $p_{\mathrm{p}} Q_{\mathrm{lp}}$ and $p_{\mathrm{p}} Q_{\mathrm{ps}}$ are leakage power of the hydraulic pump and storage power of high pressure chamber, respectively.

2.3.2. Power Balance Equation of Hydraulic Motor Driving Load. The amount of oil flowing into the hydraulic motor $Q_{p}$ is equal to the sum of flow $Q_{m}$ required to drive the motor, fluid compression $Q_{m s}$, and motor leakage $Q_{\operatorname{lm}}$. It can be expressed as follows [30]:

$$
Q_{\mathrm{p}}=Q_{\mathrm{m}}+Q_{\mathrm{ms}}+Q_{\mathrm{lm}}
$$

By multiplying both sides of (10) with the system pressure, the power balance equation of the hydraulic motor is obtained:

$$
p_{\mathrm{p}} Q_{\mathrm{p}}=p_{\mathrm{p}} Q_{\mathrm{m}}+p_{\mathrm{p}} Q_{\mathrm{ms}}+p_{\mathrm{p}} Q_{\mathrm{lm}}
$$

The torque balance equation on the motor shaft is [30]

$$
D_{\mathrm{m}} p_{\mathrm{p}} \eta_{\mathrm{m}}=T_{\mathrm{lm}}+T_{\mathrm{mf}}+J_{\mathrm{m}} \frac{d \omega_{\mathrm{m}}}{d t}+B_{\mathrm{m}} \omega_{\mathrm{m}}
$$

where $D_{\mathrm{m}}$ is the displacement of the motor, $\eta_{\mathrm{m}}$ is the mechanical efficiency of the motor, $J_{\mathrm{m}}$ is the moment of inertia converted to the motor shaft, $\omega_{\mathrm{m}}$ is the angular speed of the motor, $B_{\mathrm{m}}$ is the damping coefficient of the rotor, $T_{\mathrm{mf}}$ is the nonlinear friction torque of the motor, and $T_{\operatorname{lm}}$ is the load torque of the motor.

By multiplying the angular velocity of the motor $\omega_{m}$ at both ends of (12), the power balance equation on the motor shaft is obtained and then substituted into (11) to obtain the power model of the motor driving load as expressed in

$$
\begin{aligned}
p_{\mathrm{p}} Q_{\mathrm{p}}= & p_{\mathrm{p}} Q_{\mathrm{ms}}+p_{\mathrm{p}} Q_{\mathrm{lm}}+\omega_{\mathrm{m}} T_{\mathrm{mf}}+\omega_{\mathrm{m}} T_{\mathrm{lm}} \\
& +\omega_{\mathrm{m}} J_{\mathrm{m}} \frac{\mathrm{d} \omega_{\mathrm{m}}}{\mathrm{d} t}+B_{\mathrm{m}} \omega_{\mathrm{m}}^{2}
\end{aligned}
$$

where $p_{\mathrm{p}} Q_{\mathrm{p}}$ is the fluid power, $p_{\mathrm{p}} Q_{\mathrm{ms}}$ is the storage power of the motor oil chamber, $Q_{\mathrm{ms}}=V_{\mathrm{m}} / \beta_{\mathrm{e}} \cdot \mathrm{d} p_{\mathrm{p}} / \mathrm{d} t, V_{\mathrm{m}}$ is the volume of the high pressure chamber, $p_{\mathrm{p}} Q_{\mathrm{lm}}$ is the leakage loss power of the motor, $Q_{\operatorname{lm}}=C_{\operatorname{lm}} p_{\mathrm{p}}, C_{\mathrm{lm}}$ is the total leakage coefficient of the hydraulic motor, $\omega_{\mathrm{m}} T_{\mathrm{mf}}$ and $\omega_{\mathrm{m}} T_{\mathrm{lm}}$ are the mechanical loss power and the output power of the motor, respectively, and $\omega_{\mathrm{m}} J_{\mathrm{m}}\left(d \omega_{\mathrm{m}} / d t\right)$ and $B_{\mathrm{m}} \omega_{\mathrm{m}}^{2}$ are the power stored on the hydraulic motor shaft.

\subsection{Power Balance Equation of Induction Motor Drive} Hydraulic System. According to the analysis of the energy conversion process and the power balance equation of each link, (6) can be expressed as (14). That is, the difference between the instantaneous input power of the motor and the reactive power equals the total of the resistance loss power of the motor and the output mechanical power.

$$
P_{\text {in }}-P_{\mathrm{Q}}=P_{\mathrm{c}}+k(\mathbf{r}) P_{\mathrm{m}}
$$

In (14), $k(\mathbf{r})$ represents the connection coefficient between the motor and the hydraulic pump, which depends on their installation level and connection mode. It is a function of the space vector composed of the vibrations of $x, y$, and $z$. Ideally, it can be regarded as a constant. Here its value is set to be 1 .

By substituting (6), (9), and (13) into (14), the power balance equation of the AC motor driven hydraulic system is obtained as follows:

$$
\begin{aligned}
P_{\mathrm{in}}-P_{\mathrm{Q}}= & P_{\mathrm{c}}+J_{\mathrm{T}} \Omega \frac{\mathrm{d} \Omega}{\mathrm{d} t}+T_{\mathrm{df}} \Omega+B_{\mathrm{T}} \Omega^{2}+p_{\mathrm{p}} Q_{\mathrm{lp}} \\
& +p_{\mathrm{p}} Q_{\mathrm{ps}}+p_{\mathrm{p}} Q_{\mathrm{ms}}+p_{\mathrm{p}} Q_{\mathrm{lm}}+\omega_{\mathrm{m}} T_{\mathrm{mf}} \\
& +\omega_{\mathrm{m}} T_{\mathrm{lm}}+\omega_{\mathrm{m}} J_{\mathrm{m}} \frac{\mathrm{d} \omega_{\mathrm{m}}}{\mathrm{d} t}+B_{\mathrm{m}} \omega_{\mathrm{m}}^{2}
\end{aligned}
$$

The power on the right side of (15) is qualitatively divided into three categories: the power consumed by working load $P_{\text {es }}$, the power consumed by leakage and loss of hydraulic system $P_{\text {ls }}$ (including control valve), and the power stored in hydraulic system $P_{\text {ss }}$ (including accumulator). Therefore, the power composition of the hydraulic system and its dynamic balance equation are obtained.

$$
\begin{aligned}
P_{\mathrm{in}}-P_{\mathrm{Q}}= & P_{\mathrm{es}}+P_{\mathrm{ls}}+P_{\mathrm{ss}} \\
P_{\mathrm{es}}= & \omega_{\mathrm{m}} T_{\mathrm{lm}} \\
P_{\mathrm{ls}}= & P_{\mathrm{c}}+T_{\mathrm{df}} \Omega+\omega_{\mathrm{m}} T_{\mathrm{mf}}+p_{\mathrm{p}} Q_{\mathrm{lp}}+p_{\mathrm{p}} Q_{\mathrm{lm}} \\
P_{\mathrm{ss}}= & J_{\mathrm{T}} \Omega \frac{\mathrm{d} \Omega}{\mathrm{d} t}+B_{\mathrm{T}} \Omega^{2}+p_{\mathrm{p}} Q_{\mathrm{ps}}+p_{\mathrm{p}} Q_{\mathrm{ms}} \\
& +\omega_{\mathrm{m}} J_{\mathrm{m}} \frac{\mathrm{d} \omega_{\mathrm{m}}}{\mathrm{d} t}+B_{\mathrm{m}} \omega_{\mathrm{m}}^{2}
\end{aligned}
$$

The working characteristic of the hydraulic system is that loss power, storage power, and load power influence each other and change all the time. If the loss of power increases, the efficiency of the hydraulic system decreases and the system temperature and failure rate increase. When the energy storage power is low, the hydraulic system fluctuation will become larger and impact resistance and stability will become worse. When the load power is too high, the energy storage power decreases, the loss power increases, the controllability of the hydraulic system decreases, and the failure rate increases. These characteristics make it difficult to carry out the research on state monitoring and fault diagnosis of the hydraulic systems. Therefore, the research on state monitoring, fault diagnosis, and power matching should be carried out based on the dynamic characteristics, energy structure, and the matching situation of the hydraulic systems.

\section{Proposed Monitoring Method}

3.1. Active Power Circle (APC) and Reactive Power Circle $(R P C)$. Given a perfectly symmetrical three-phase power supply induction motor, after low-pass filter processing, the phase voltage and current signal of the motor stator are expressed as follows[31]: 


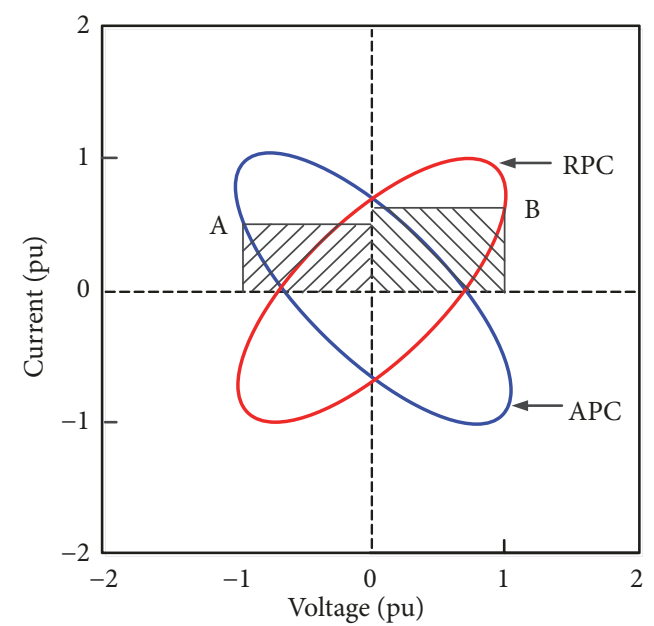

Figure 2: Active power circle (APC) and reactive power circle (RPC).

$$
\begin{aligned}
& u_{j}=x=f(t) B \cos \left[2 \pi f(t) t+\varphi_{u}\right] \\
& i_{j}=y=A \cos \left[2 \pi f(t) t+\varphi_{i}\right]
\end{aligned}
$$

where $j=a, b, c$ represents the indexes of the phases, $f(t)$ is the output frequency of the converter, $A$ is the amplitude of the current, $B$ is the ratio of phase voltage amplitude to frequency, $\psi_{u}$ and $\psi_{i}$ are the initial phases of the phase voltage and current, respectively, $\psi_{u}-\psi_{i}=\varphi$ is the phase difference, and $\cos \varphi$ is the power factor.

$$
B=\frac{\sqrt{2} U}{f(t)} \approx \frac{\sqrt{2} \times 4.44 f(t) K_{1} N_{1} \Phi}{f(t)}=6.28 K_{1} N_{1} \Phi
$$

According to the Lissajous graphic principle [32], in a twodimensional plane of voltage as the horizontal axis and current as the vertical axis, the graph drawn by (20) is an ellipse centered at the origin.

By introducing $\omega(t) t+\psi_{i}=\alpha$ into (20), $\cos \alpha$ and $\sin \alpha$ can be obtained by

$$
\begin{aligned}
& \cos \alpha=\frac{y}{A} \\
& \sin \alpha=\frac{(y / A) \cos \varphi-(x / f(t) B)}{\sin \varphi}
\end{aligned}
$$

Substituting (22) and (23) into trigonometric functions $\cos ^{2} a+\sin ^{2} a=1$, finally the equation of the ellipse in Descartes coordinate system is obtained as expressed by

$$
\frac{x^{2}}{[f(t) B]^{2}}-\frac{2 x y}{f(t) A B} \cos \varphi+\frac{y^{2}}{A^{2}}-\sin ^{2} \varphi=0
$$

Equation (24) is defined as the reactive power circle (RPC) equation and its graph is defined as reactive power circle shown in Figure 2.

In the same way, by adding 90 degree to the phase of voltage signal in (20), the active power circle (APC) equation is obtained as expressed by (25), and the corresponding graph of the APC is showed in Figure 2.

$$
\frac{x^{2}}{[f(t) B]^{2}}+\frac{2 x y}{f(t) A B} \sin \varphi+\frac{y^{2}}{A^{2}}-\cos ^{2} \varphi=0
$$

Figure 2 shows that in the coordinate plane of voltage as the horizontal axis and current as the vertical axis, the APC and RPC are both ellipses and centered at the origin of the Cartesian coordinates. On the trajectory of each power circle, any point $A\left(u_{A}, i_{A}\right)$ or $B\left(u_{B}, i_{B}\right)$ represents the instantaneous value of the voltage and current at the stator side of the motor. The rectangular area enclosed by the vertical line from the point to the coordinate axis presents the instantaneous active or reactive power, respectively.

3.2. Functional Relation between Power and Graphic Characteristic Quantity. Assuming that the power supply frequency is $f_{1}$, taking the single-phase RPC as an example, the RPC area expressed by $a_{\mathrm{RPC}}$ can be calculated using Green's formula, as expressed in (27).

$$
\begin{aligned}
x & =f_{1} B \cos \left[2 \pi f_{1} t+\varphi_{u}\right] \\
y & =A \cos \left[2 \pi f_{1} t+\varphi_{i}\right] \\
\quad t \in[0, T], T=\frac{1}{f_{1}} & \\
a_{\mathrm{RPC}} & =\frac{1}{2} \oint_{L} x \mathrm{~d} y-y \mathrm{~d} x=\frac{1}{2} \int_{0}^{T}\left(x \frac{\mathrm{d} y}{\mathrm{~d} t}-y \frac{\mathrm{d} x}{\mathrm{~d} y}\right) \mathrm{d} t \\
& =\pi f_{1} A B \sin \varphi
\end{aligned}
$$

Then, the relationship between reactive power $Q$ [33] and $a_{\mathrm{RPC}}$ is

$$
Q=3 \times \frac{A}{\sqrt{2}} \times \frac{f_{1} B}{\sqrt{2}} \times \sin \varphi=\frac{3 f_{1} A B}{2} \sin \varphi=\frac{3}{2 \pi} a_{\mathrm{RPC}}
$$

Similarly, the relationship between the active power $P$ and the APC area is

$$
P=\frac{3}{2 \pi} a_{\mathrm{APC}}
$$

Equations (28) and (29) show that the APC and RPC areas are proportional to the active and reactive power, respectively. Therefore, changes of APC and RPC can directly reflect changes of active power and reactive power, respectively.

In Figure 3, the area of the bounding rectangle of APC and RPC is expressed as $a_{\mathrm{BR}}$ and $L_{1}$ and $L_{2}$ are side lengths of the bounding rectangle. Since the center of the bounding rectangle is the origin, the side length $L_{1}$ and $L_{2}$ is twice the maximum amplitudes of voltage and current, respectively, as shown in (30). Then, area of the bounding rectangle is obtained as shown in (31).

$$
\begin{aligned}
L_{1} & =2 f(t) B \\
L_{2} & =2 A \\
a_{\mathrm{BR}} & =L_{1} L_{2}
\end{aligned}
$$




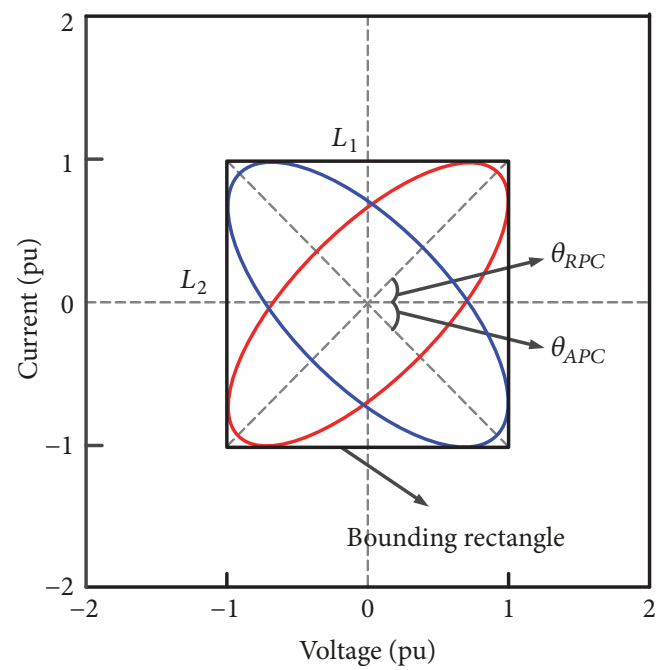

FIgURE 3: Characteristic quantity in RPC and APC. $L_{1}$ and $L_{2}$ are sides length of the bounding rectangle. Reactive tilt angle $\theta_{R P C}$ and active tilt angle $\theta_{A P C}$ are the angles between $x$ axis and major axis of $\mathrm{RPC}$ and APC, respectively.

The three-phase apparent power of the inverter-fed motor is calculated by function $S=3 U I$.

$$
\begin{aligned}
S & =3 U I=3 \times \frac{f(t) B}{\sqrt{2}} \times \frac{A}{\sqrt{2}}=3 \times \frac{L_{1}}{2 \sqrt{2}} \times \frac{L_{2}}{2 \sqrt{2}} \\
& =\frac{3}{8} L_{1} L_{2}=\frac{3}{8} a_{\mathrm{BR}}
\end{aligned}
$$

Obviously, it is linearly related to the area of the bounding rectangle as expressed in (32). Variation of the area can directly reflect the variation of apparent power of the motor.

The angle between horizontal line and the major axis of the RPC and APC is defined as reactive tilt angle $\theta_{\mathrm{RPC}}$ and active tilt angle $\theta_{\mathrm{APC}}$, respectively. By applying coordinate transformation to (24), the standard equation of the ellipse is obtained as shown in

$$
\begin{aligned}
& \left(\frac{\cos ^{2} \theta_{\mathrm{RPC}}}{[f(t) B]^{2} \sin ^{2} \varphi}+\frac{\sin ^{2} \theta_{\mathrm{RPC}}}{A^{2} \sin ^{2} \varphi}\right. \\
& \left.-\frac{\cos \varphi}{f(t) A B \sin ^{2} \varphi} \sin 2 \theta_{\mathrm{RPC}}\right) x^{2} \\
& +\left(\frac{\sin ^{2} \theta_{\mathrm{RPC}}}{[f(t) B]^{2} \sin ^{2} \varphi}+\frac{\cos ^{2} \theta_{\mathrm{RPC}}}{A^{2} \sin ^{2} \varphi}\right. \\
& \left.+\frac{\cos \varphi}{f(t) A B \sin ^{2} \varphi} \sin 2 \theta_{\mathrm{RPC}}\right) y^{2} \\
& +\left(-\frac{2 \cos \varphi}{f(t) A B \sin ^{2} \varphi} \cos 2 \theta_{\mathrm{RPC}}-\frac{\sin 2 \theta_{\mathrm{RPC}}}{[f(t) B]^{2} \sin ^{2} \varphi}\right. \\
& \left.+\frac{\sin 2 \theta_{\mathrm{RPC}}}{A^{2} \sin ^{2} \varphi}\right) x y=1
\end{aligned}
$$

In (33), according to the standard equation of ellipse, the third term on the left is equal to zero, as expressed in

$$
\begin{gathered}
\frac{2 \cos \varphi}{f(t) A B \sin ^{2} \varphi} \cos 2 \theta_{\mathrm{RPC}}+\frac{\sin 2 \theta_{\mathrm{RPC}}}{[f(t) B]^{2} \sin ^{2} \varphi} \\
-\frac{\sin 2 \theta_{\mathrm{RPC}}}{A^{2} \sin ^{2} \varphi}=0
\end{gathered}
$$

By solving (34), the value of the reactive tilt angle $\theta_{\mathrm{RPC}}$ is obtained as shown in

$$
\theta_{\mathrm{RPC}}= \begin{cases}\frac{1}{2} \arctan \frac{2 f(t) A B \cos \varphi}{\left[f^{2}(t) B^{2}-A^{2}\right]}, & f(t) B \neq A \\ \pm \frac{\pi}{4}, & f(t) B=A\end{cases}
$$

Similarly, the active tilt angle $\theta_{\mathrm{APC}}$ can be obtained as shown in

$$
\theta_{\mathrm{APC}}= \begin{cases}\frac{1}{2} \arctan \frac{2 f(t) A B \sin \varphi}{\left[A^{2}-f^{2}(t) B^{2}\right]}, & f(t) B \neq A \\ \pm \frac{\pi}{4}, & f(t) B=A\end{cases}
$$

In Figure 3, changes of the tilt angles present different changing rules under different working conditions. When the motor is running in the motoring condition, according to its operating principle, there should be $\cos \varphi<0$ and $\sin \varphi>0$; that is, the motor consumes active and reactive power. Under this condition, if $f_{1} B>A$, the reactive tilt angle $\theta_{\mathrm{RPC}}$ is at $(0, \pi / 4)$, and the active angle $\theta_{\mathrm{APC}}$ is at $(-\pi / 4,0)$; if $f_{1} B<$ $A, \theta_{\mathrm{RPC}}$ is at $(\pi / 4, \pi / 2)$, and $\theta_{\mathrm{APC}}$ is at $(-\pi / 2,-\pi / 4)$, which means that the reactive tilt angle $\theta_{\mathrm{RPC}}$ is in the first quadrant, and the active tilt angle $\theta_{\mathrm{APC}}$ is in the fourth quadrant.

When the motor is running in generation condition, $\cos \varphi<0$ and $\sin \varphi>0$, the motor emits active power and consumes the reactive power to establish magnetic field. Under this condition, if $f_{1} B>A$, the reactive tilt angle $\theta_{\mathrm{RPC}}$ is at $(-\pi / 4,0)$ and the active angle $\theta_{\mathrm{APC}}$ is at $(-\pi / 4,0)$; if $f_{1} B<A, \theta_{\mathrm{RPC}}$ is at $(-\pi / 2,-\pi / 4)$ and $\theta_{\mathrm{APC}}$ is at $(-\pi / 2,-\pi / 4)$, which means both $\theta_{\mathrm{RPC}}$ and $\theta_{\mathrm{APC}}$ are in the fourth quadrant.

Based on the analysis above, the following conclusion can be drawn: when the motor is running under electric condition, the active tilt angle is in the first quadrant and the reactive tilt angle is in the fourth quadrant; when the motor is generating, both angles are in the fourth quadrant. Therefore, the characteristics of motor load condition can be judged according to the tilt angles of the power circles.

3.3. Apparent, Active, and Reactive $(A / A / R)$ Power Circles Graph. In electrotechnics, alternating current power is defined as the flow rate of energy through a given node. In the average energy of a complete cycle of an AC waveform, the power flow that transfers energy in one direction is called active power $P$; the power flow that is reserved and returned to the power supply is called reactive power $Q$; the product of the voltage effective value and the current effective value is the apparent power $S$. The relationship between the three powers is as follows:

$$
S^{2}=P^{2}+Q^{2}
$$




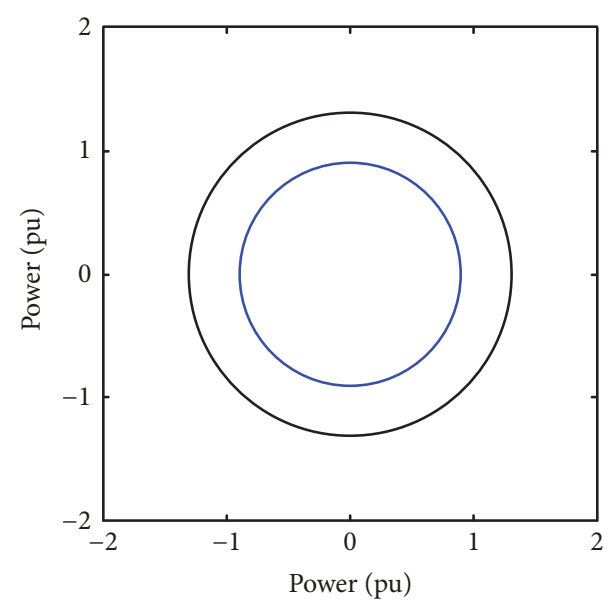

FIgure 4: Apparent, Active and Reactive (A/A/R) Power circles graph. The graph is used to visually show the dynamic relationship among apparent, active, and reactive power.

Combining (37) with (28), (29), and (32), the power circle equations are obtained, as shown in (38), by which the $\mathrm{A} / \mathrm{A} / \mathrm{R}$ power circles of the motor is established in the same coordinate system, and the graph is shown in Figure 4.

$$
\begin{aligned}
A_{\text {outer circle }} & =\pi S^{2}=\pi\left(\frac{3}{8} a_{\mathrm{BR}}\right)^{2} \\
A_{\text {inner circle }} & =\pi P^{2}=\pi\left(\frac{3}{2 \pi} a_{\mathrm{APC}}\right)^{2} \\
A_{\text {ring }} & =\pi Q^{2}=\pi\left[\left(\frac{3}{8} a_{\mathrm{BR}}\right)^{2}-\left(\frac{3}{2 \pi} a_{\mathrm{APC}}\right)^{2}\right]
\end{aligned}
$$

In Figure 4, the area of the outer circle, inner circle, and the ring represents the square of apparent power, active power, and reactive power, respectively. Changes of the power circles correspond to changes of the working conditions, which will be verified by experiments. The A/A/R power circles graph can visually reflect the dynamic relationship among the apparent power, active power, and reactive power under varying operating conditions of the motor driven hydraulic system.

\section{Experimentation}

\subsection{Experiment Setup and Signals Preprocessing}

4.1.1. Experiment Platform. The test bench and its schematic diagram are shown in Figure 5. It is a pump-controlled variable frequency and variable displacement compound speed regulating hydraulic system, which mainly consists of power source, closed hydraulic transmission system, hydraulic loading system, and measurement and control system. The power source of the test bench includes distribution system, frequency converter, and three-phase asynchronous motor. The closed hydraulic transmission system includes variable pump, variable motor, and hydraulic control components such as relief valve. The hydraulic loading system includes gear pump and pilot proportional relief valve for loading. The measurement and control system includes sensors, multifunction data acquisition card, industrial computer, and software platforms.

The frequency converter controls the motor 1 to drive the variable displacement piston pump 3 and then adjusts the input flow of the variable piston motor 6 by changing the speed or displacement of the pump 3. Loading valve 9 is used to regulate the outlet pressure of gear pump 8 and then control the load torque of variable piston motor 6 . Safety valve 5 limits the maximum working pressure of the hydraulic system. The slippage pump 4 is used to supplement the leakage flow of pump 3 and motor 6 , and the oil pressure is controlled by the relief valve 12 . Flow meter 21 measures the high pressure side flow of the hydraulic system. Pressure sensors 19 and 22 measure the high pressure chamber pressure of variable pump 3 and variable motor 6 , respectively. Pressure sensor 13 is used to measure the pressure of the system. Speed and torque sensors 2 and 7 measure the torque and speed of variable pump and motor, respectively.

In the experiments, the speed of variable displacement pump is controlled by adjusting the frequency of the inverter, and the loading signal is adjusted by controlling the input of the loading valve. In this way, the pressure of the gear pump oil-out line is generated, and the loading torque is generated on the motor shaft.

4.1.2. Acquisition of Electrical Signals. As shown in Figure 6, converter 2 processes the three-phase alternating current (AC) supplied by power supply 1 and drives the motor to rotate with the AC signal output from the converter. At the same time, sensor 7 measures the voltage and current signals after frequency conversion. Since the voltage and current signals output from the inverter are no longer standard sinusoidal waves because of their harmonics, it is impossible to accurately describe the phase information of voltage and current signals. Therefore, conditioning circuit 8 is used to obtain the voltage and current signals which are close to sinusoidal waveform. Then the digital signal is acquired by $\mathrm{A} / \mathrm{D}$ acquisition card 9 and sent to the computer for further signal processing.

The experiment uses an electric parameter data acquisition system which enables a noninvasive measurement with great accuracy [34]. In the conditioning circuit, MFB thirdorder Butterworth low-pass filter as shown in Figure 7 is adopted.

The waveforms of the collected voltage and current signal are shown in Figures 8(a) and 8(b). It can be seen that although the signal is filtered in the hardware circuit, nonfundamental frequency interference still exists in the voltage and current signals. In order to retain useful information for analysis and filter out interference information, the fundamental frequency components of signals are further extracted by low-pass filtering in computer software. Since the motor circuit of the test bench is triangular connection, shown in Figure 5(c), the line current is converted into phase current by phase-shifting and amplitude-modulation processing before filtering. The smooth sinusoidal waveforms of voltage and current are obtained after filtering, as shown in Figures $8(\mathrm{c})$ and $8(\mathrm{~d})$. 


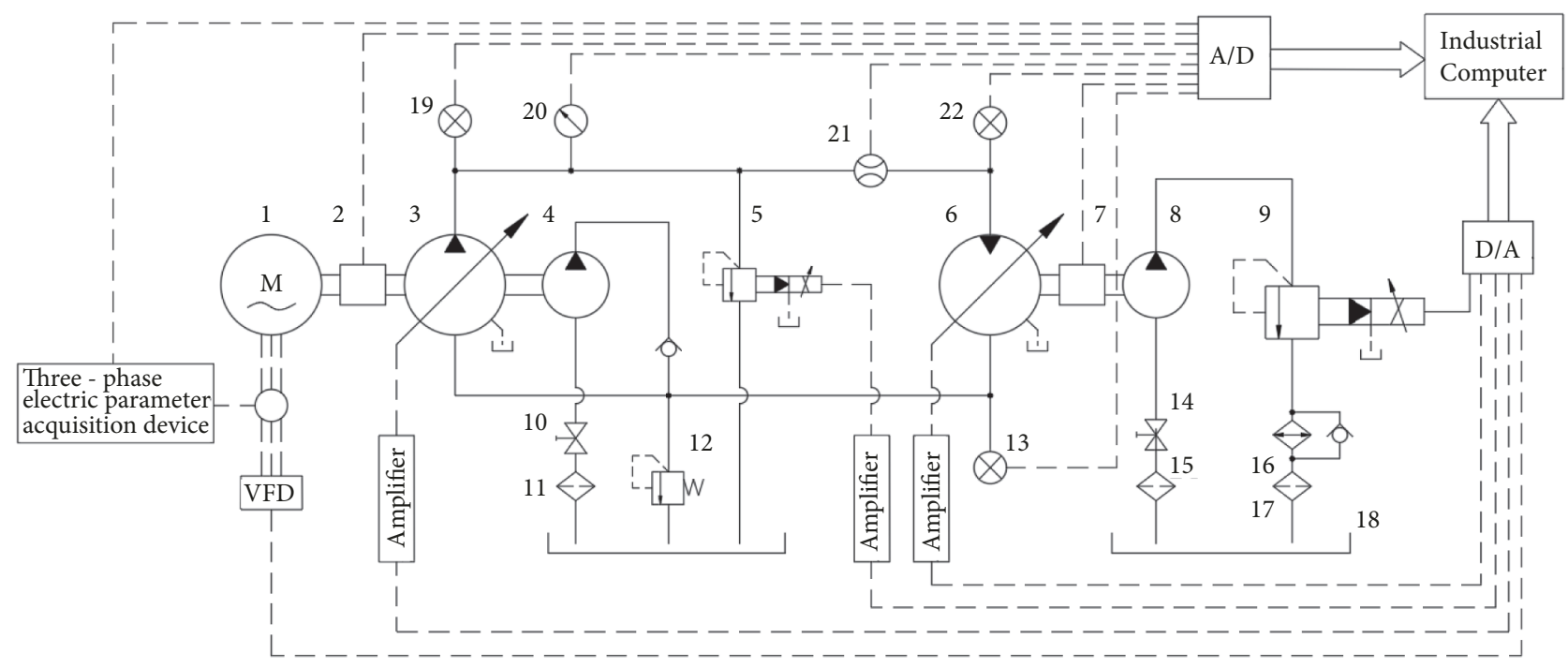

(a)

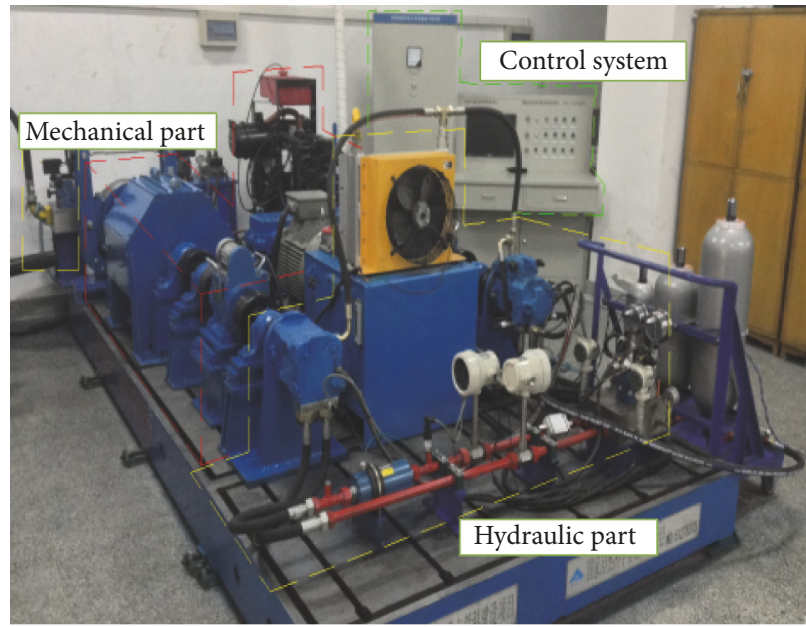

(b)

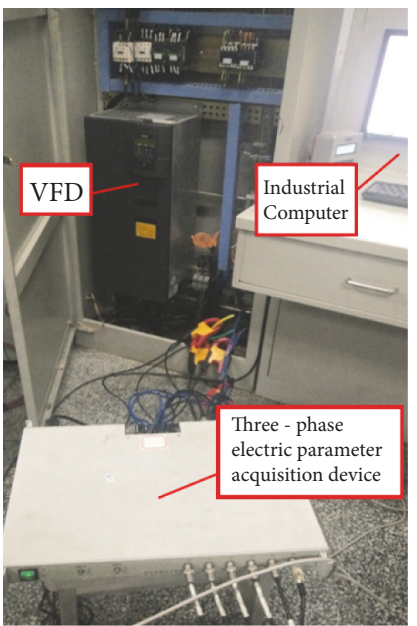

(c)

FIGURE 5: (a) Schematic diagram of experiment platform. 1-variable frequency motor, 2/7-torque and speed sensors, 3-variable piston pump, 4slippage pump, 5-safety valve, 6-variable piston motor, 8-gear pump, 9-proportional relief valve, 10/14-globe valve, 11/15/17-filter, 12-relief valve, 13/19/22-pressure sensor, 16-radiator, 18-tank, 20-temperature sensor, and 21-flow meter. (b) Hydromechatronics test platform. (c) Wiring diagram of three-phase electric parameter acquisition.

In addition, in order to facilitate calculation and analysis, the per-unit values of voltage and current signals (i.e., the ratio of voltage and current signals to the reference value based on no-load operation voltage and current signals) are used.

\subsection{Experiment during Varying Speed Condition}

4.2.1. Monitoring under Frequency Conversion Acceleration Condition. The variation law of power circles and tilt angles during frequency conversion acceleration is shown in Figures 9 and 10. In the experiment, the motor speed is set to change from 100 to $600 \mathrm{r} / \mathrm{min}$ (the speed is proportional to the frequency), and the sampling frequency is $5000 \mathrm{~Hz}$.
In Figure 9, the areas of APC and RPC increase with the speed, while the tilt angles decrease. The vertical edge of the bounding rectangle $L_{2}$ (corresponding to the current amplitude) does not change significantly during the acceleration process, while the vertical edge $L_{1}$ (corresponding to voltage amplitude) increases gradually during the acceleration. Figure 10 shows the variation law of A/A/R power and tilt angle during frequency conversion acceleration. The higher the supply frequency, the larger the areas of RPC and APC, and the smaller the tilt angles $\theta_{\mathrm{RPC}}$ and $\theta_{\mathrm{APC}}$.

4.2.2. Monitoring under Sinusoidal Frequency Condition. The variation law of power circles and tilt angles under sinusoidal frequency condition is shown in Figures 11 and 12, where 


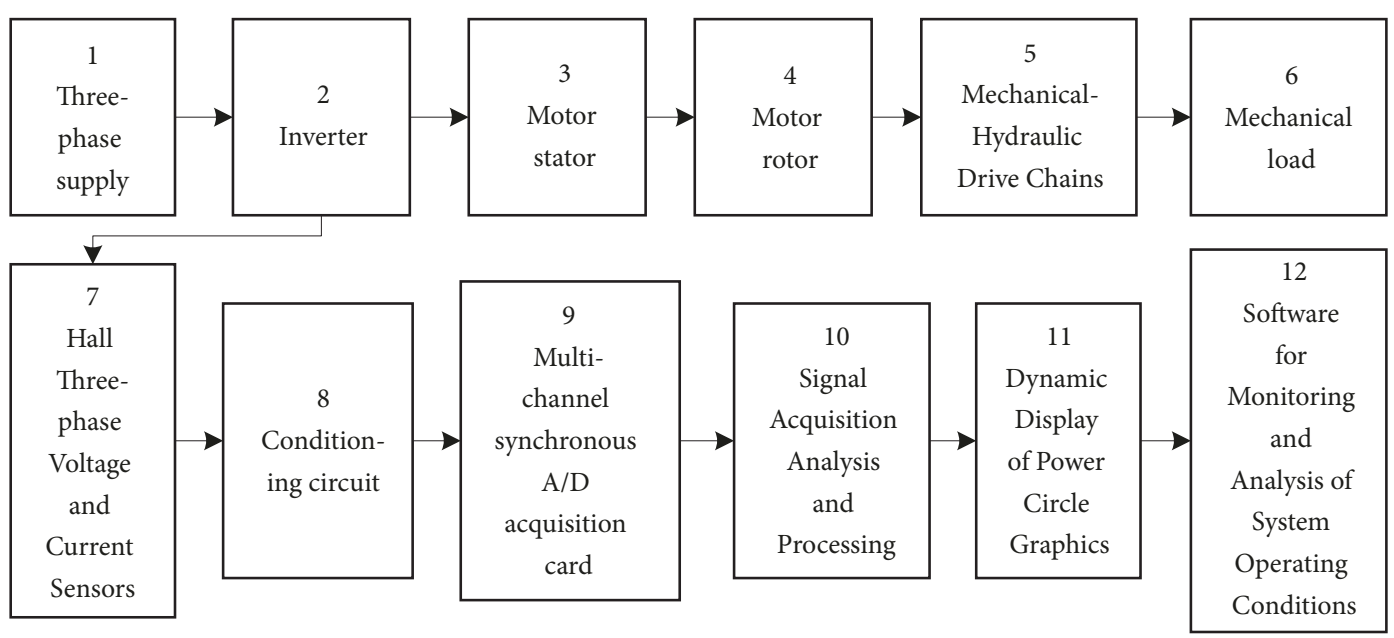

FIGURE 6: Principle diagram of online monitoring for frequency conversion hydraulic system.

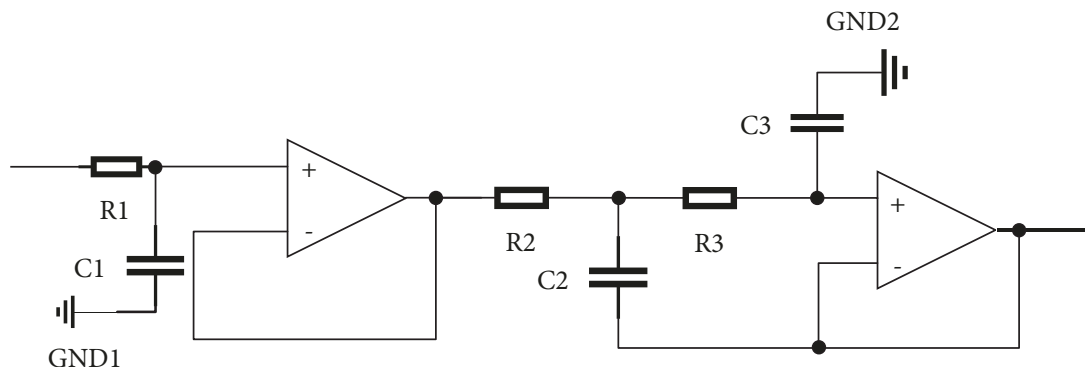

FIGURE 7: Schematic diagram of third-order Butterworth low-pass filter circuit.

the speed of the motor is set to change sinusoidally between $100 \mathrm{r} / \mathrm{min}$ and $600 \mathrm{r} / \mathrm{min}$. The tilt angles and powers vary periodically with the change of motor speed. When the frequency sinusoidally increases, the areas of APC and RPC increase, while the active tilt angle $\theta_{\mathrm{APC}}$ and reactive tilt angle $\theta_{\mathrm{RPC}}$ decrease. When the frequency sinusoidally decreases, the area of APC and RPC decrease, while the active tilt angle $\theta_{\mathrm{APC}}$ and reactive tilt angle $\theta_{\mathrm{RPC}}$ increase.

\subsection{Monitoring under Constant Frequency. Experiments} under typical working conditions of the hydraulic system, such as loading, unloading, overloading, and impact, are carried out with a constant frequency of $50 \mathrm{~Hz}$. The minimum and maximum load pressure are $0 \mathrm{MPa}$ and $15 \mathrm{MPa}$, respectively.

4.3.1. Loading and Unloading Conditions. Figure 13(a) shows the variation law of power circles under a loading condition. When the system loads, both the area of APC and the area of RPC increase gradually, the ellipse rotates clockwise centering at the origin, and the tilt angle decreases. At the same time, it can be seen that $L_{1}$ (corresponding to voltage amplitude) changes a little, while $L_{2}$ (corresponding to the current amplitude) increases gradually during the process of loading. When system load reaches to $15 \mathrm{Mpa}$, it begins to unload, both of the areas decrease gradually, and the tilt angles increase gradually. During the process of unloading $L_{1}$ remains unchanged, while $L_{2}$ decreases gradually. Figure 13(b) shows the variation law of tilt angles under load-adding and load-reducing conditions. It can be seen that the greater the system load is, the greater the change rate of tilt angles is. The active power circle rotates from clockwise to counterclockwise with the increase and decrease of load.

4.3.2. Overload Protection Condition and Cyclic Impact Condition. Under overloading conditions, as shown in Figure 14, the change trend of the loading process is consistent with the trend under loading conditions shown in Figure 13. When the maximum pressure is reached, overflow protection occurs in the system, which makes the pressure no longer increase. At the same time, the system load no longer increases; similarly, the graphic area and tilt angles no longer change significantly. When the hydraulic system is subjected to periodic impact, the graphical characteristics change periodically, as shown in Figure 15.

4.3.3. Motor Winding Fault Condition. Figure 16 shows the three-phase active power circles under the condition that the motor has electrical faults, including out of phase and short circuit. Figure 16(a) shows the APC of three phases with A-phase short circuit fault. It is obvious that when the 


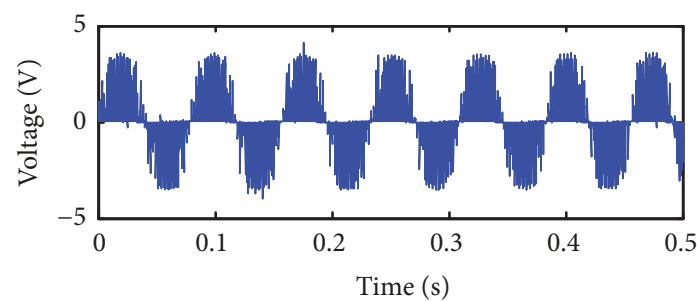

(a)

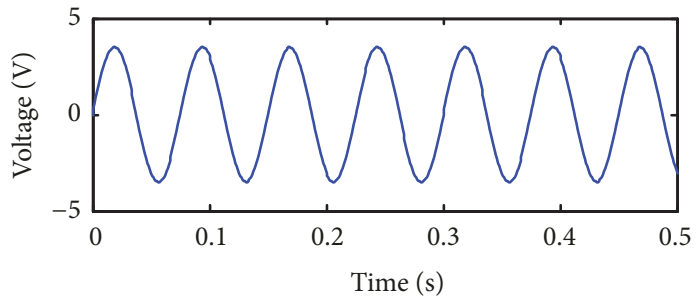

(c)

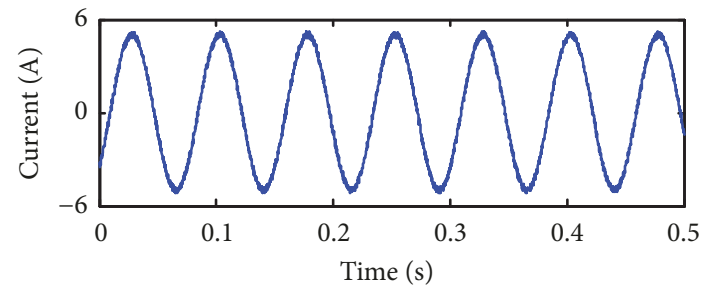

(b)

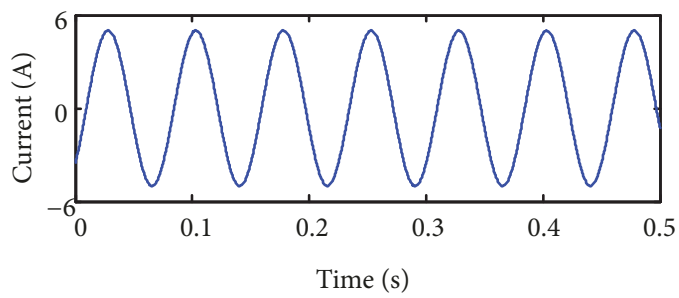

(d)

FIGURE 8: Comparison of voltage and current signals before and after preprocessing. (a) Voltage signals acquired. (b) Current signals acquired. (c) Fundamental component of Voltage. (d) Fundamental component of current.
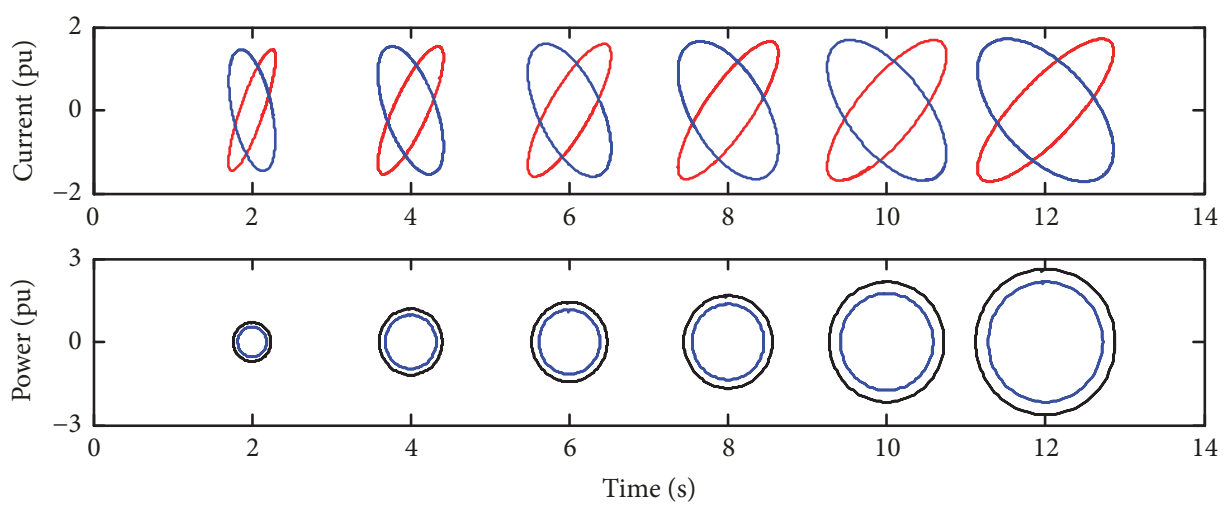

FIGURE 9: Dynamic change process of power circles during frequency conversion acceleration.

motor operates in the state of short circuit (i.e., phase-A short circuit), voltage of phase-A is zero, voltages of the other two phase are the same, and both are much larger than the normal. Current of phase-A is the largest and current of the other two phases are the same and much larger than the normal. When the motor runs a phase-lacked state (i.e., phase- $C$ disconnection), as shown in Figure 16(b), current of phase$\mathrm{C}$ is zero, currents of the other two phases are the same and larger than the normal, the active power of phase-A is the largest, and phase- $\mathrm{B}$ is the second.

\section{Conclusion}

In this paper, a monitoring approach of the power condition for inverter-fed motor driven hydraulic system is proposed. The dynamic power balance equation of $\mathrm{AC}$ motor driven hydraulic system is established to analyze the conversion and coupling process of the electric, mechanical, and hydraulic energy. The amplitude and phase information of the input voltage and current signals of the AC motor are used to fuse the dynamic power circle. And then, the power state and its dynamic change process of the hydraulic system are monitored based on the power circle. The theoretical and experimental explorations show the following.

(1) The area of APC and RPC is proportional to the power supply frequency and system load, which directly expresses the active and reactive power of the variable frequency motor. The bounding rectangle has a linear relationship with the apparent power indicating the load state of the power supply. The power factor of the motor can be calculated directly from the apparent power and active power.

(2) Dynamic power circle $A / A / R$ obtained from the active power, reactive power, and apparent power can directly reflect the power changes of motor, which facilitates online monitoring of the power matching process between the motor and hydraulic system.

(3) The characteristics of tilt angle change can identify the typical working conditions of inverter-fed hydraulic system such as frequency conversion acceleration, 


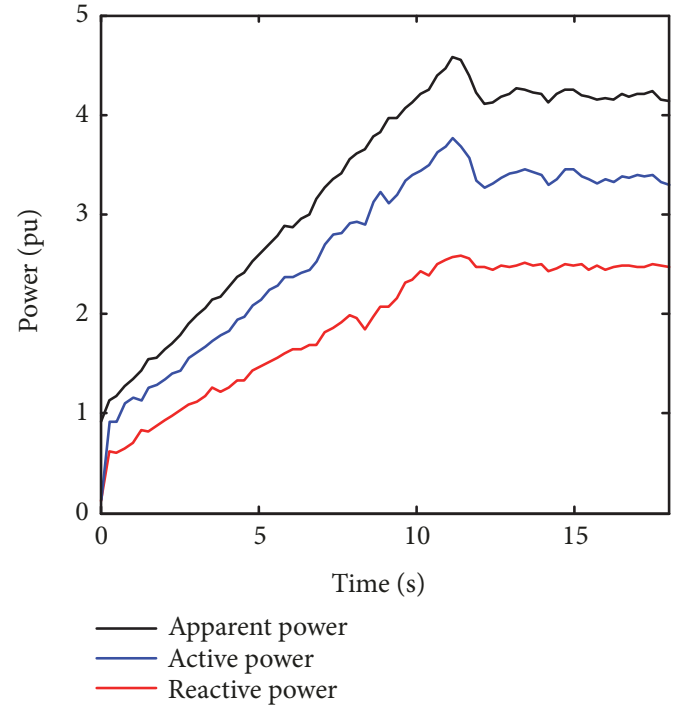

(a)

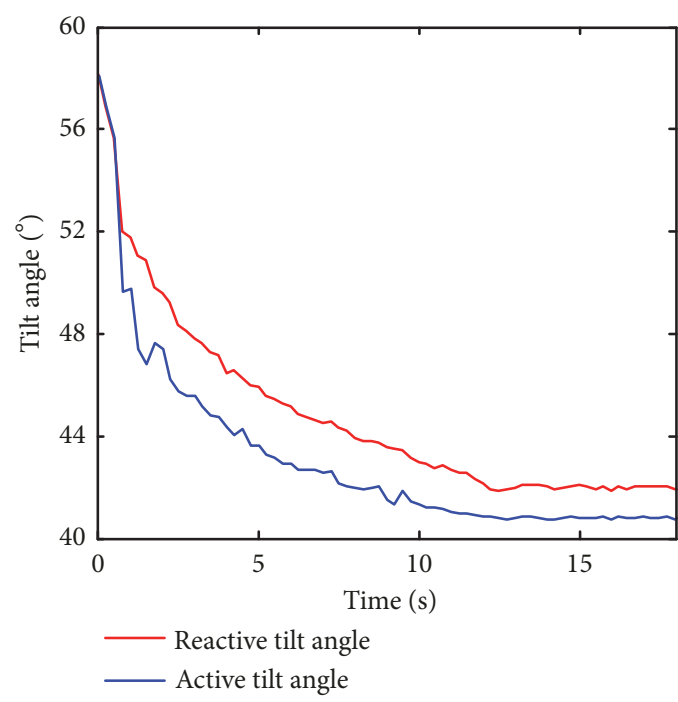

(b)

FIGURE 10: Curves of powers and tilt angles during frequency conversion acceleration. (a) Active power, reactive power, and apparent power. (b) Active tilt angle and reactive tilt angle.
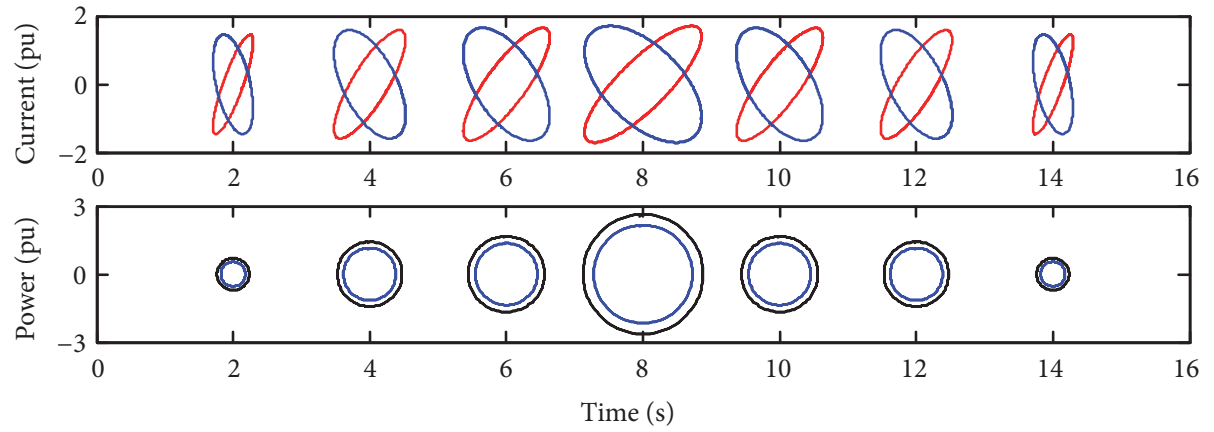

FIGURE 11: Dynamic change process of power circles during sinusoidal frequency conversion.

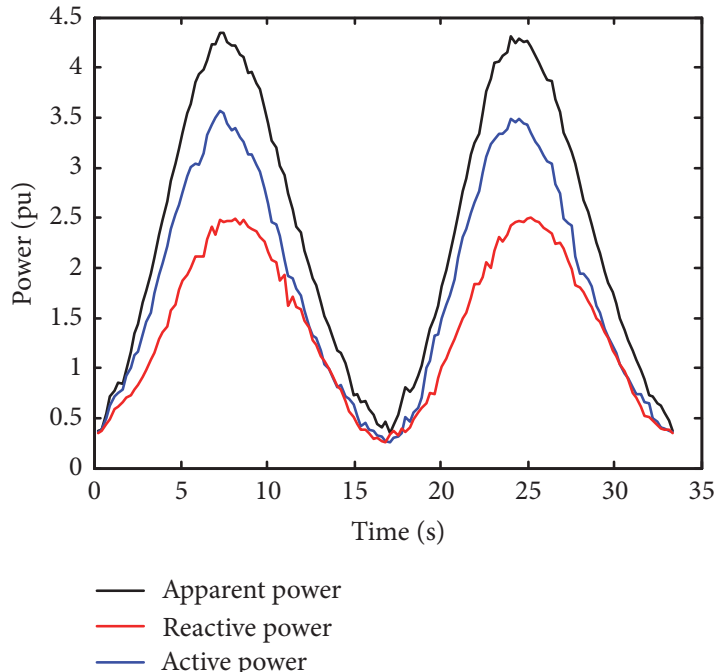

(a)

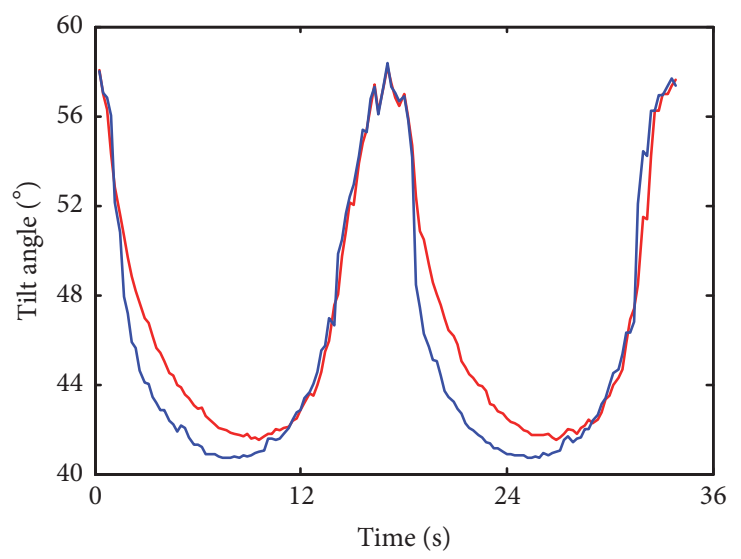

_ Reactive tilt angle

- Active tilt angle

(b)

FIGURE 12: Curves of powers and tilt angles during sinusoidal frequency conversion. (a) Active power, reactive power, and apparent power. (b) Active tilt angle and reactive tilt angle. 

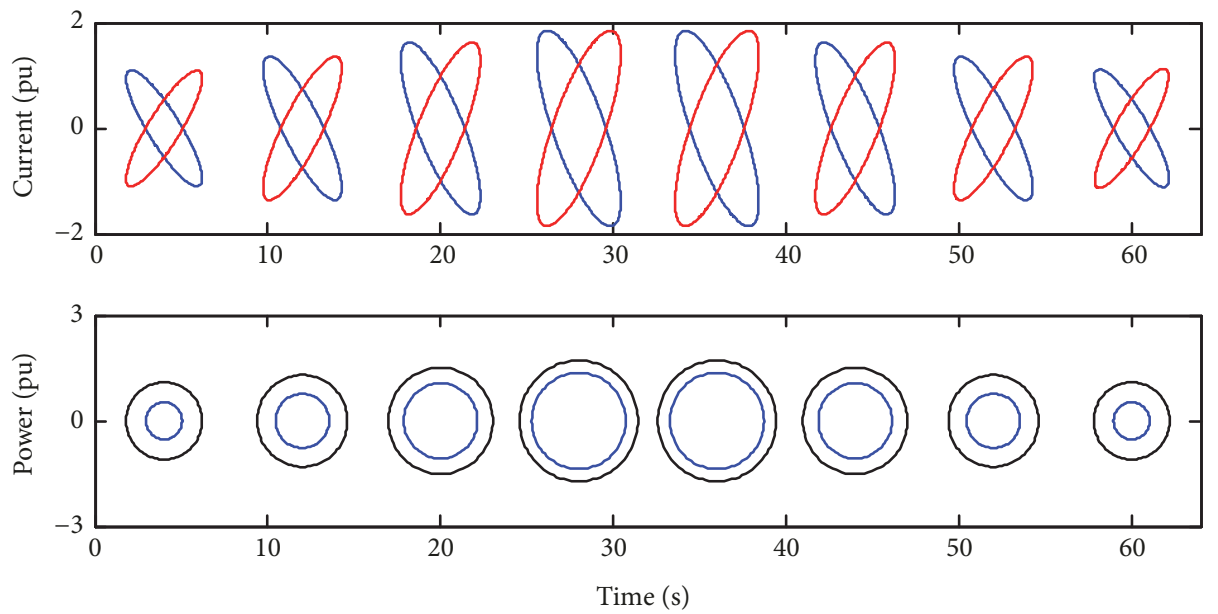

(a)

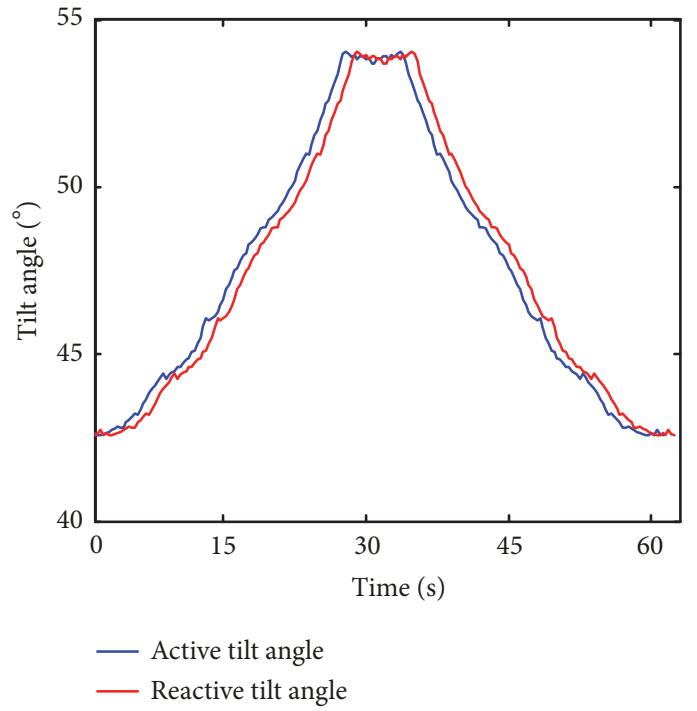

(b)

FIGURE 13: Changes of power circles and tilt angles under loading and unloading conditions. (a) Dynamic change process of power circles. (b) Active tilt angle and reactive tilt angle.

loading, unloading, impact, and overload. In addition, it is worth noticing that the tilt angle of APC and $\mathrm{RPC}$ is sensitive, and its change process contains more dynamic operation information of the system, which needs to be further excavated and utilized.

(4) Higher harmonics in electrical signals may cause additional losses or even equipment faults in the system. The energy distribution of harmonic components also contains characteristic information that reflects hydraulic system faults. Therefore, more studies should be conducted to separate power source interference, extract the amplitude and phase information of the harmonic components of electrical signals by using the appropriate signal processing methods, and draw holographic power circle to obtain fault characteristics of the system.

The proposed method offers an inexpensive and novel alternative to the traditional monitoring ways based on the pressure, flow, and vibration signals which are unstable and easily disturbed. Furthermore, the graphical monitoring method directly reflects the working condition of the system and can be realized online. It is hoped that the study will help foster the creation of a condition monitoring and diagnosis method of the hydraulic system based on holographic power circle (amplitude and phase of each harmonic component).

\section{Nomenclature}

Symbols

$T_{\mathrm{e}}$ : Electromagnetic torque

$p_{\mathrm{p}}$ : Outlet pressure of the hydraulic pump

$R_{\mathrm{e}}:$ Resistance

$Z_{\Omega}$ : Mechanical impedance

$Z_{\mathrm{Y}}$ : Liquid impedance 

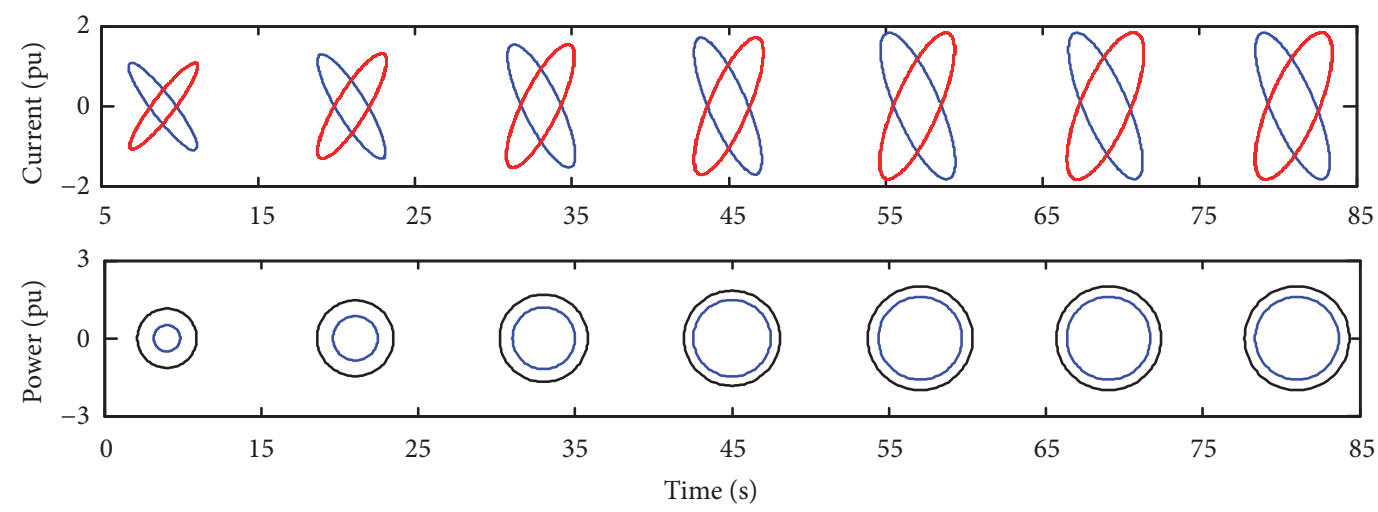

(a)

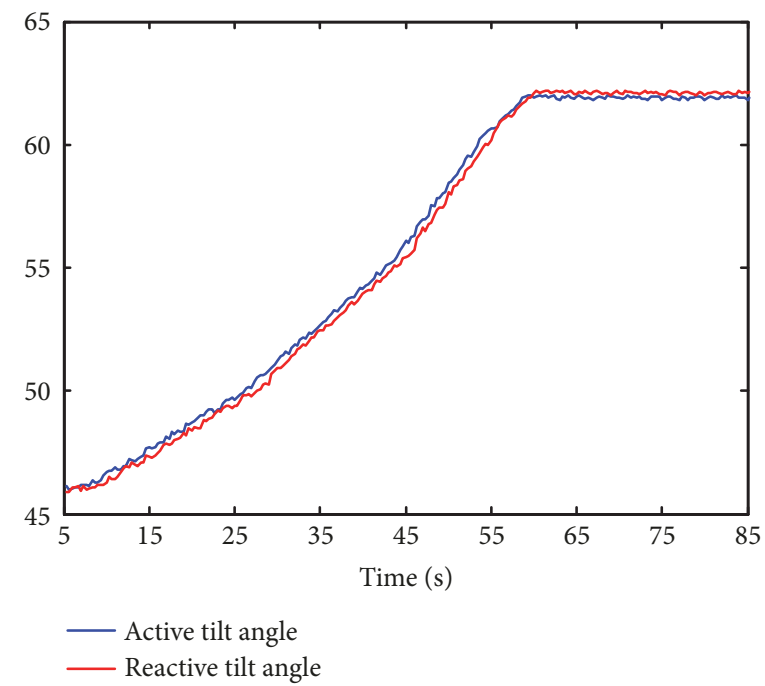

(b)

FIGURE 14: Changes of power circles and tilt angles under overloading condition. (a) Dynamic change process of power circles. (b) Active tilt angle and reactive tilt angle.

\begin{tabular}{|c|c|c|c|}
\hline$e:$ & Motor eccentricity & $T_{\mathrm{df}}:$ & Nonlinear friction torque of the \\
\hline$P_{\text {in }}:$ & Input power of the motor & & motor \\
\hline$\Delta P_{\mathrm{R}}:$ & $\begin{array}{l}\text { Electrical resistance loss power of } \\
\text { the motor }\end{array}$ & $B_{\mathrm{T}}:$ & $\begin{array}{l}\text { Damping coefficient of the motor } \\
\text { rotor shaft }\end{array}$ \\
\hline $\begin{array}{l}P_{\mathrm{ms}}: \\
P_{\mathrm{m}}:\end{array}$ & $\begin{array}{l}\text { Storage power of the motor } \\
\text { Output mechanical power of the }\end{array}$ & $Q_{\mathrm{L}}=D_{\mathrm{p}} \omega_{\mathrm{r}} / 2 \pi n_{\mathrm{p}}$ & $\begin{array}{l}\text { Theoretical flow of the hydraulic } \\
\text { pump }\end{array}$ \\
\hline$\Delta P_{\mathrm{m}}:$ & $\begin{array}{l}\text { motor } \\
\text { Mechanical loss power }\end{array}$ & $D_{p}:$ & $\begin{array}{l}\text { Displacement of the hydraulic } \\
\text { pump }\end{array}$ \\
\hline$\Delta P_{1}:$ & $\begin{array}{l}\text { Leakage loss power of the } \\
\text { hydraulic pump }\end{array}$ & $Q_{\mathrm{p}}:$ & Output flow of the hydraulic pump \\
\hline$P_{\mathrm{ps}}:$ & Storage power of the high pressure & $Q_{\mathrm{lp}}=C_{\mathrm{lp}} p_{\mathrm{p}}$ & Leakage of the hydraulic pump \\
\hline & $\begin{array}{l}\text { chamber of the hydraulic pump } \\
\text { Output power of the hydraulic }\end{array}$ & $C_{\mathrm{lp}}:$ & $\begin{array}{l}\text { Total leakage coefficient of } \\
\text { hydraulic pumps }\end{array}$ \\
\hline$J_{\mathrm{T}}:$ & $\begin{array}{l}\text { pump } \\
\text { Moment of inertia on the shaft of }\end{array}$ & $Q_{\mathrm{ps}}=V_{\mathrm{p}} / \beta_{\mathrm{e}}\left(\mathrm{d} p_{\mathrm{p}} / \mathrm{d} t\right)$ & $\begin{array}{l}\text { Flow caused by hydraulic } \\
\text { compression }\end{array}$ \\
\hline$\Omega=\omega_{\mathrm{r}} / n_{\mathrm{p}}:$ & $\begin{array}{l}\text { the motor } \\
\text { Mechanical angular velocity }\end{array}$ & $V_{\mathrm{p}}:$ & $\begin{array}{l}\text { Volume of the high pressure } \\
\text { chamber of the hydraulic pump }\end{array}$ \\
\hline$n_{\mathrm{p}}:$ & Number of pole-pairs & $\beta_{\mathrm{e}}:$ & Elastic modulus of the oil \\
\hline$T_{\mathrm{m}}:$ & $\begin{array}{l}\text { Output mechanical torque of the } \\
\text { motor }\end{array}$ & $\begin{array}{l}D_{\mathrm{m}}: \\
\eta_{\mathrm{m}}:\end{array}$ & $\begin{array}{l}\text { Displacement of the motor } \\
\text { Mechanical efficiency of the motor }\end{array}$ \\
\hline
\end{tabular}



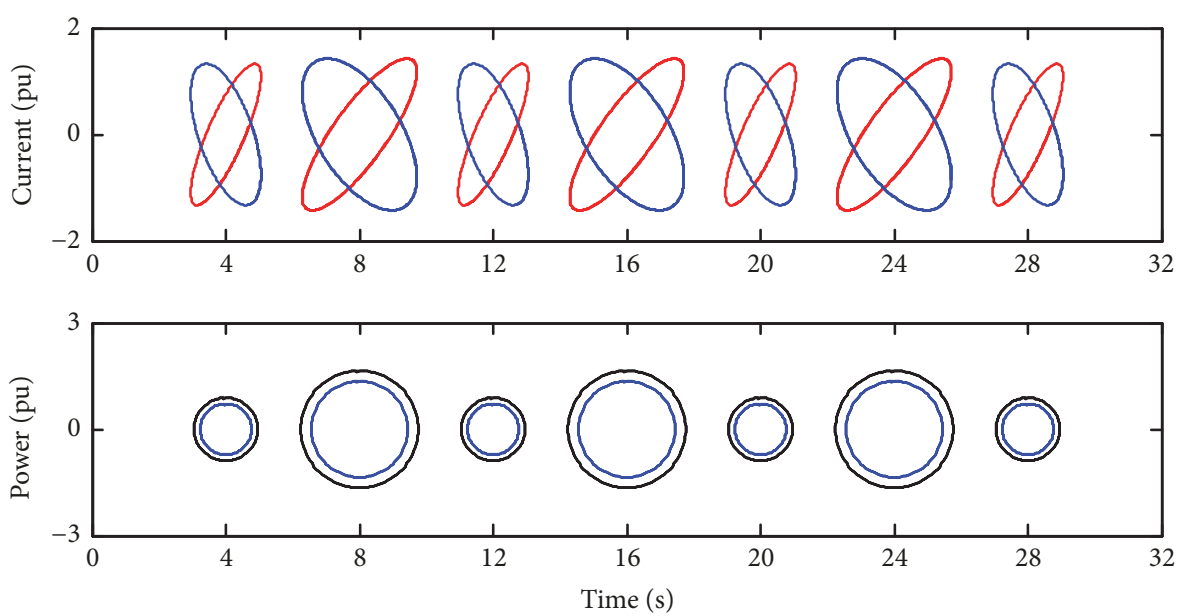

(a)

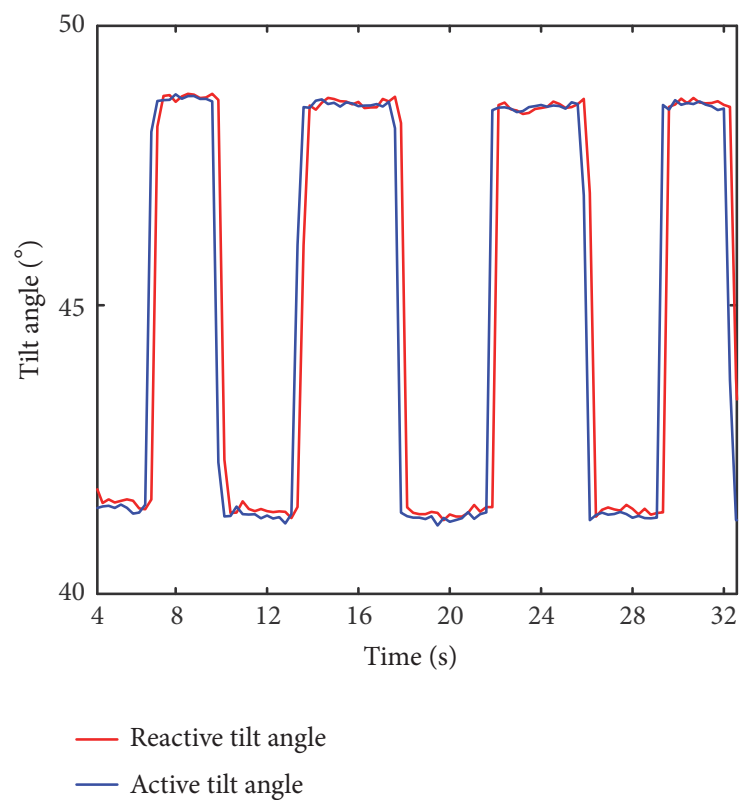

(b)

FIGURE 15: Changes of power circles and tilt angles under periodic impact condition. (a) Dynamic change process of power circles. (b) Active tilt angle and reactive tilt angle.

$J_{\mathrm{m}}$ : Moment of inertia converted to the motor shaft

$\omega_{\mathrm{m}}$ : Angular speed of the motor

$B_{\mathrm{m}}$ : Damping coefficient of the rotor

$T_{\mathrm{mf}}$ : Nonlinear friction torque of the motor

$T_{\mathrm{lm}}$ : Load torque of the motor

$\theta_{\mathrm{RPC}}$ : Tilt angle of reactive power circle

$\theta_{\text {APC }}$ : Tilt angle of active power circle

Abbreviations

EMF: Electromotive force

APC: Active power circle
RPC: $\quad$ Reactive power circle

A/A/R power circles: Apparent, active, and reactive power circles.

\section{Data Availability}

The data used to support the findings of this study are included within the article.

\section{Conflicts of Interest}

The authors declare that there is no conflict of interest regarding the publication of this paper. 

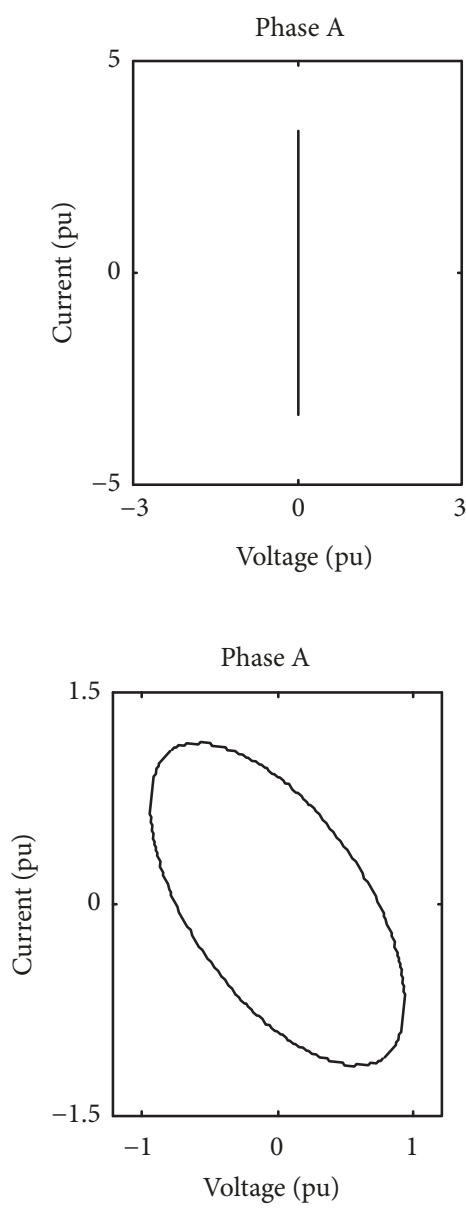

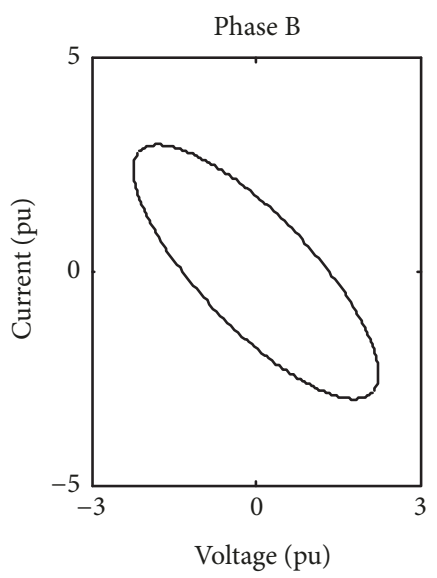

(a)

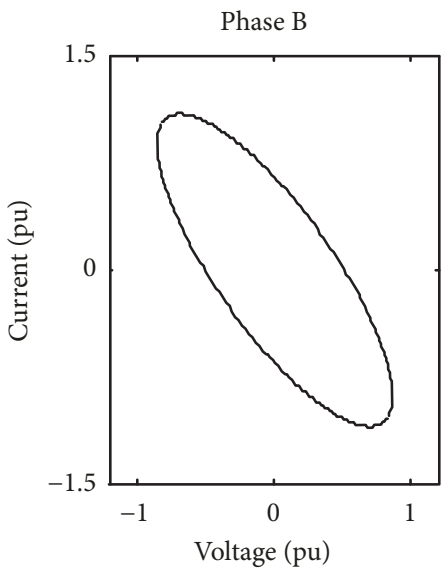

(b)
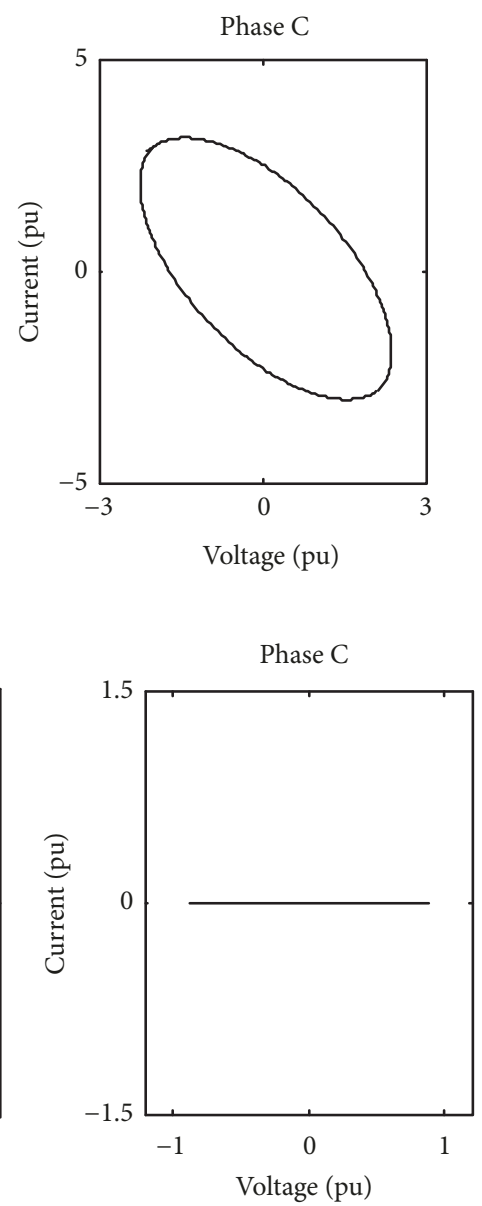

FIGURE 16: Three-phase active power circles in the case of motor winding failure. (a) Phase-A short circuit. (b) Phase-C disconnection.

\section{Acknowledgments}

The work of this paper is supported by the National Natural Science Foundation of China (No. 51675399).

\section{References}

[1] E. B. Agamloh, "Power and efficiency measurement of motorvariable-frequency drive systems," IEEE Transactions on Industry Applications, vol. 53, no. 1, pp. 766-773, 2016.

[2] S. Ramesh, S. D. Ashok, and S. Nagaraj, "An energy conservation strategy using variable frequency drive for a hydraulic clamping system in a cnc machine," Materials Today: Proceedings, vol. 5, no. 5, pp. 13504-13513, 2018.

[3] V. K. A. Shankar, S. Umashankar, S. Paramasivam, and N. Hanigovszki, "A comprehensive review on energy efficiency enhancement initiatives in centrifugal pumping system," Applied Energy, vol. 181, pp. 495-513, 2016.

[4] D. J. Sadey, L. M. Taylor, and R. F. Beach, "Proposal and development of a high voltage variable frequency alternating current power system for hybrid electric aircraft," in Proceedings of the 14th International Energy Conversion Engineering Conference, 2016, USA, July 2016.
[5] T. Tukia, S. Uimonen, M.-L. Siikonen, C. Donghi, and M. Lehtonen, "High-resolution modeling of elevator power consumption," Journal of Building Engineering, vol. 18, pp. 210-219, 2018.

[6] A. Helbig, "Injection moulding machine with electric-hydrostatic drives," in Proceedings of the 3rd International Fluid Power Conference (3. IFK), vol. 1, Aachen, Germany, 2002.

[7] M. Riera-Guasp, J. A. Antonino-Daviu, and G.-A. Capolino, "Advances in electrical machine, power electronic, and drive condition monitoring and fault detection: state of the art," IEEE Transactions on Industrial Electronics, vol. 62, no. 3, pp. 17461759, 2015.

[8] G. Singh and V. N. A. Naikan, "Detection of half broken rotor bar fault in VFD driven induction motor drive using motor square current MUSIC analysis," Mechanical Systems and Signal Processing, vol. 110, pp. 333-348, 2018.

[9] F. Malrait, A. K. Jebai, and K. Ejjabraoui, "Power conversion optimization for hydraulic systems controlled by variable speed drives," Journal of Process Control, 2017.

[10] A. Prudhom, J. Antonino-Daviu, H. Razik, and V. ClimenteAlarcon, "Time-frequency vibration analysis for the detection of motor damages caused by bearing currents," Mechanical Systems and Signal Processing, vol. 84, pp. 747-762, 2017. 
[11] M. Akar, "Detection of a static eccentricity fault in a closed loop driven induction motor by using the angular domain order tracking analysis method," Mechanical Systems and Signal Processing, vol. 34, no. 1-2, pp. 173-182, 2013.

[12] P. Stefaniak, R. Zimroz, J. Obuchowski, P. Sliwinski, and M. Andrzejewski, "An effectiveness indicator for a mining loader based on the pressure signal measured at a bucket's hydraulic cylinder," Procedia Earth and Planetary Science, vol. 15, pp. 797805, 2015.

[13] J.-H. Jung, J.-J. Lee, and B.-H. Kwon, "Online diagnosis of induction motors using MCSA," IEEE Transactions on Industrial Electronics, vol. 53, no. 6, pp. 1842-1852, 2006.

[14] M. Sahraoui, A. Ghoggal, S. Guedidi, and S. E. Zouzou, "Detection of inter-turn short-circuit in induction motors using ParkHilbert method," International Journal of Systems Assurance Engineering and Management, vol. 5, no. 3, pp. 337-351, 2014.

[15] V. F. Pires, M. Kadivonga, J. F. Martins, and A. J. Pires, "Motor square current signature analysis for induction motor rotor diagnosis," Measurement, vol. 46, no. 2, pp. 942-948, 2013.

[16] I. Bravo-Imaz, H. Davari Ardakani, Z. Liu, A. García-Arribas, A. Arnaiz, and J. Lee, "Motor current signature analysis for gearbox condition monitoring under transient speeds using wavelet analysis and dual-level time synchronous averaging," Mechanical Systems and Signal Processing, vol. 94, pp. 73-84, 2017.

[17] S. H. Kia, H. Henao, and G.-A. Capolino, "A comparative study of acoustic, vibration and stator current signatures for gear tooth fault diagnosis," in Proceedings of the 2012 20th International Conference on Electrical Machines, ICEM 2012, pp. 1514-1519, Marseille, France, September 2012.

[18] S. Rajagopalan, T. G. Habetler, R. G. Harley, T. Sebastian, and B. Lequesne, "Current/voltage-based detection of faults in gears coupled to electric motors," IEEE Transactions on Industry Applications, vol. 42, no. 6, pp. 1412-1420, 2006.

[19] J. M. Bossio, G. R. Bossio, and C. H. De Angelo, "Angular misalignment in induction motors with flexible coupling," in Proceedings of the 35th Annual Conference of the IEEE Industrial Electronics Society, IECON 2009, pp. 1033-1038, Porto, Portugal, November 2009.

[20] M. M. Stopa, B. J. Cardoso Filho, and C. B. Martinez, "Incipient detection of cavitation phenomenon in centrifugal pumps," IEEE Transactions on Industry Applications, vol. 50, no. 1, pp. 120-126, 2014.

[21] S. Alabied, O. Hamomd, A. Daraz, F. Gu, and A. D. Ball, "Fault diagnosis of centrifugal pumps based on the intrinsic timescale decomposition of motor current signals," in Proceedings of the 23rd IEEE International Conference on Automation and Computing, ICAC 2017, pp. 1-6, UK, September 2017.

[22] L. Gu, Y. Zhang, and D. Qiu, "Study on detection of running condition for hydraulic power system based on current signal," Chinese Journal of Mechanical Engineering, vol. 37, no. 6, pp. 6165, 2001.

[23] S. Rajagopalan, T. G. Habetler, R. G. Harley, T. G. Sebastian, and B. Lequesne, "Current/voltage-based detection of faults in gears coupled to electric motors," IEEE Transactions on Industry Applications, vol. 42, no. 6, pp. 1412-1420, 2006.

[24] G. Y. Qiu, Electric Circuit, Advanced Education Press, Beijing, China, 5th edition, 2006.

[25] Y.-J. Wang and M.-H. Lee, "A method for balancing a singlephase loaded three-phase induction generator," Energies, vol. 5, no. 9, pp. 3534-3549, 2012.
[26] C. H. Zhang, X. N. Xin, and K. Li, Ac Motor Frequency Control and Application, China Machine Press, Beijing, 2008.

[27] P. Krause, O. Wasynczuk, S. Sudhoff, and S. Pekarek, Analysis of Electric Machinery and Drive Systems, John Wiley \& Sons, Inc., Hoboken, NJ, USA, 2013.

[28] M. Meng and Z. L. Xu, "Analysis of the powers in asynchronous motors based on arbitrary reference fame," Journal of Tianjin University, vol. 6, pp. 362-365, 2006.

[29] Y. M. Tang, Electric Machinery, China Machine Press, Beijing, China, 5th edition, 2014.

[30] Z. F. Guan, Hydraulic Transmission System, China Machine Press, Beijing, China, 3th edition, 2004.

[31] A. Kucuker and M. Bayrak, "Detection of mechanical imbalances of induction motors with instantaneous power signature analysis," Journal of Electrical Engineering \& Technology, vol. 8, no. 5, pp. 1116-1121, 2013.

[32] H. Xu, G. Lu, Z. Wang, H. Yu, G. Qian, and Z. Lu, "Research on transformer winding fault detection method based on the voltage and current characteristics of LISSAJOUS," in Proceedings of the 2nd International Conference on Intelligent Computing and Cognitive Informatics (ICICCI 2015), Singapore, September 2015.

[33] R. Mugalimov, V. Kosmatov, and A. Mugalimova, "Mathematical description of the electric drive based on the energy-saving induction motor with individual reactive power compensation," Russian Internet Journal of Industrial Engineering, vol. 2, pp. 7889, 2016.

[34] Y. Lei, L. C. Gu, and P. J Liu, "Developing three-phase electrical signal real-time monitoring system for electric power drive system," Mechanical Science and Technology for Aerospace Engineering, vol. 32, no. 8, pp. 1149-1152, 2013. 


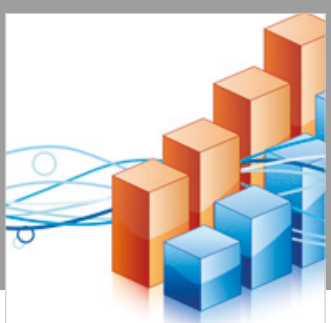

Advances in

Operations Research

\section{-n-m}
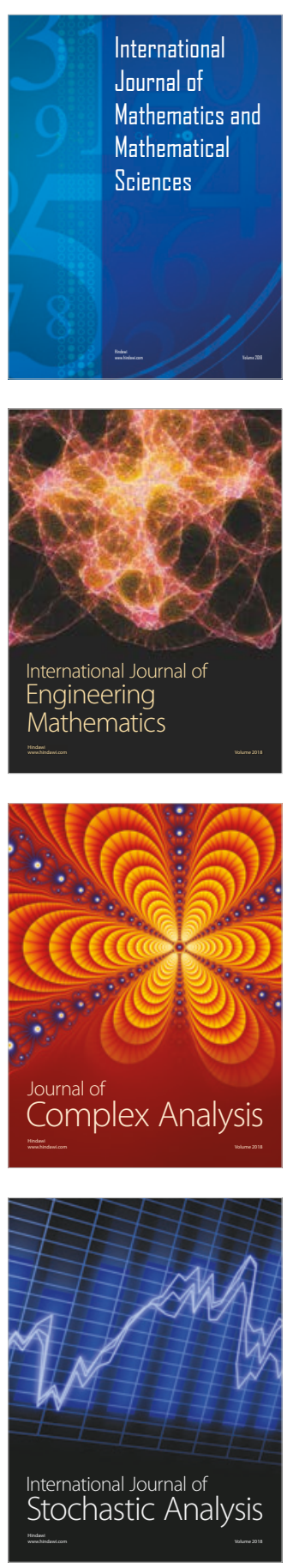
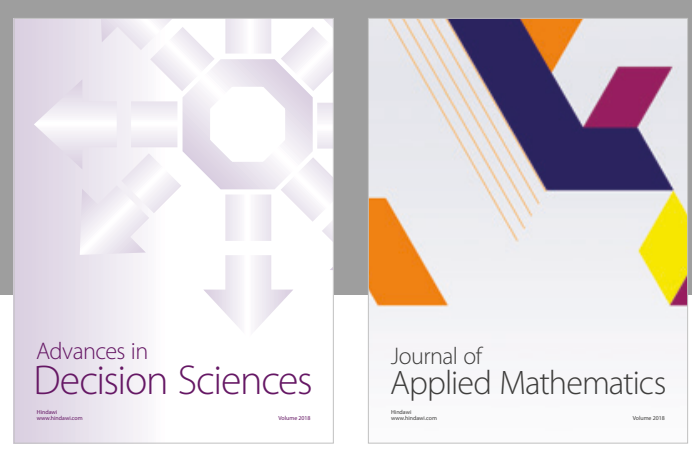

Journal of

Applied Mathematics
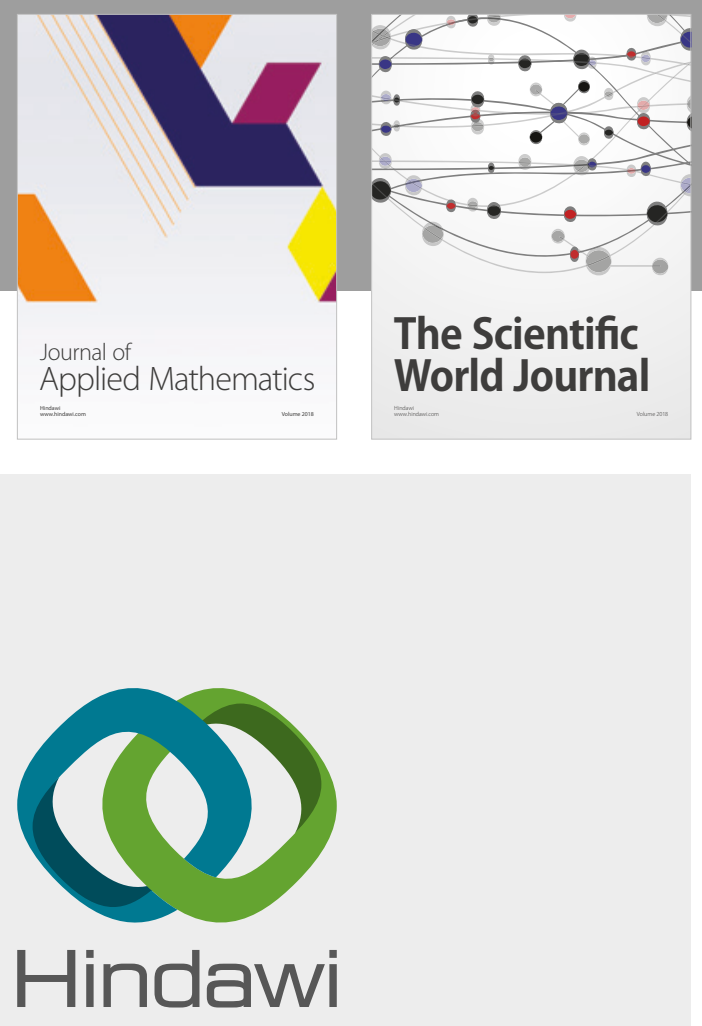

Submit your manuscripts at

www.hindawi.com

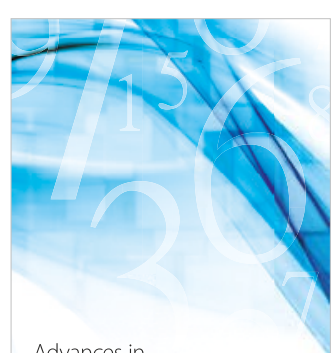

Advances in
Numerical Analysis
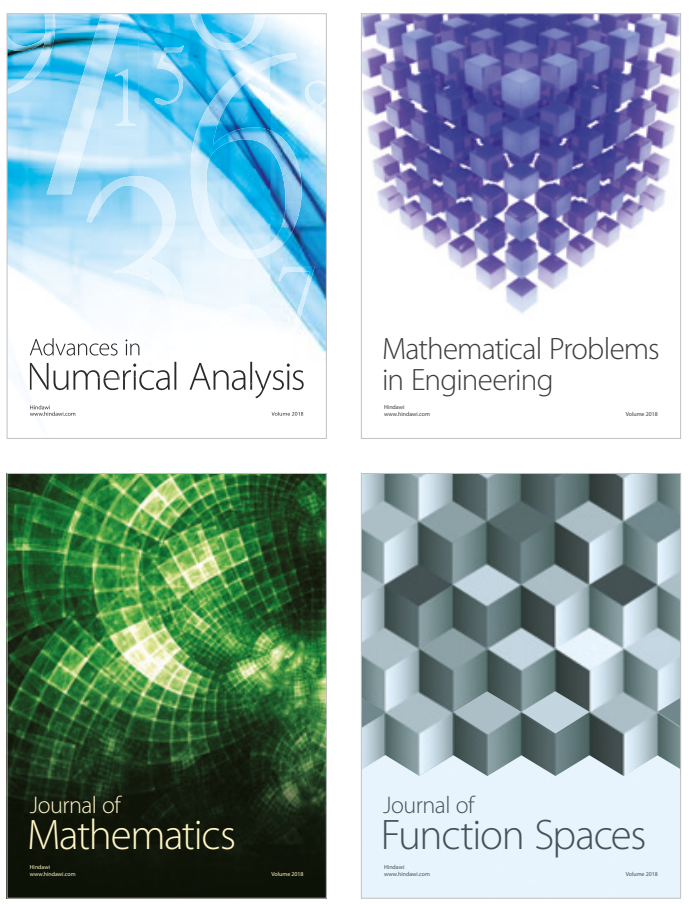

Mathematical Problems in Engineering

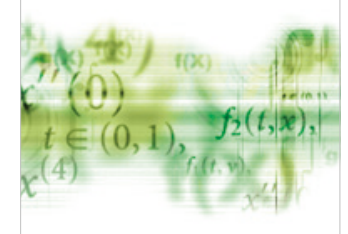

International Journal of

Differential Equations

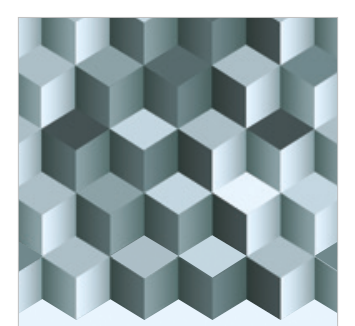

Journal of

Function Spaces

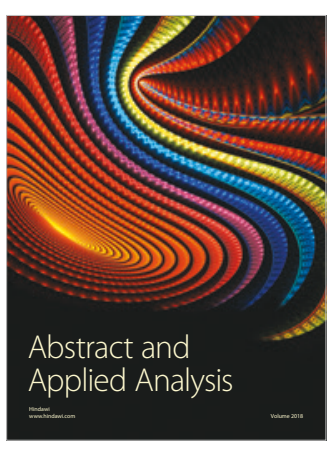

The Scientific

World Journal

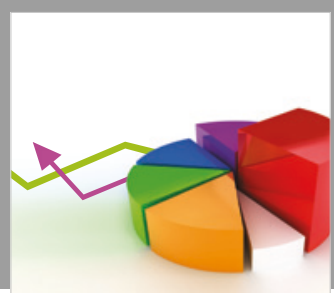

Journal of

Probability and Statistics
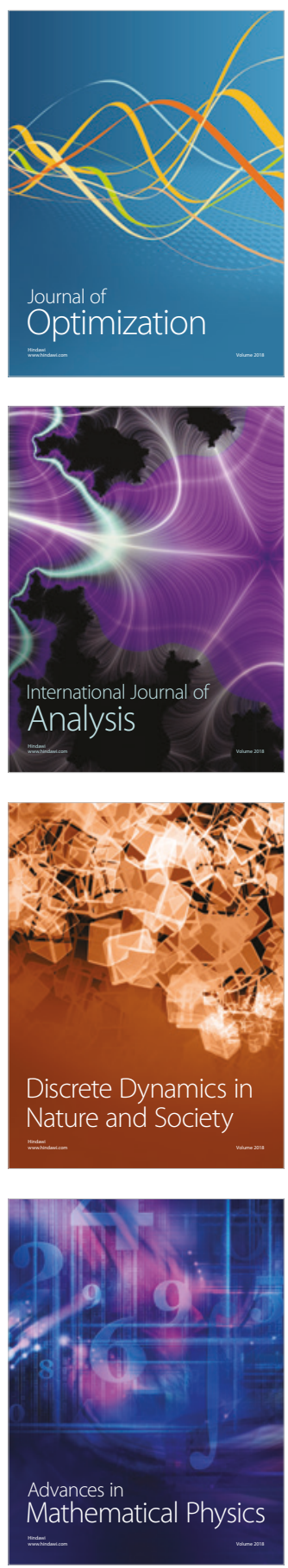